\title{
50 Anos da Revista DAD0S: Uma Análise Bibliométrica do seu Perfil Disciplinar e Temático*
}

\author{
Luiz Augusto Campos \\ João Feres Júnior \\ Fernando Guarnieri
}

Universidade do Estado do Rio de Janeiro (UERJ), Rio de Janeiro, RJ, Brasil. E-mail: lascampos@iesp.uerj.br

\section{INTRODUÇÃO}

T o clássico A Estrutura das Revoluções Científicas, o filósofo Thomas 1 Kuhn argumenta que o uso de artigos como principal meio de comunicação científica é uma das características da "ciência normal" que a distingue das formas pré-paradigmáticas de produção de conhecimento (Kuhn, 1962:13). Hoje em dia, mais de meio século após a publicação do livro de Kuhn, as Ciências Sociais parecem ainda não ter atingido o pleno estágio paradigmático - há, na verdade, muitas razões para argumentar que elas não devam jamais atingi-lo (Veyne, 1998:174). É inegável, contudo, que a produção de artigos científicos tem se tornado mais e mais central nas Ciências Sociais. Várias são as causas que concorrem para esse fato, entre elas o crescimento contínuo da pesquisa e da pós-graduação, as induções institucionais e financeiras das agências de fomento, a estruturação da profissão em torno de critérios de produtividade e a mudança da cultura acadêmica, de formas mais aristocráticas para práticas mais democráticas de produção e circulação de conhecimento.

\footnotetext{
* Os autores gostariam de agradecer a Thyago Simas de Oliveira pelo desenvolvimento do algoritmo que viabilizou a raspagem das informações dos fascículos de DADOS indexados no SciELO; a Marcia Rangel Candido, Poema Eurístenes, Cleissa Regina e Marcell Machado que codificaram manualmente os artigos da revista anteriores a 1996.
}

DADOS - Revista de Ciências Sociais, Rio de Janeiro, vol. 60, n3, 2017, pp. 623 a 661. 
No presente artigo apresentamos um estudo da DADOS - Revista de Ciências Sociais, responsável, mais do que qualquer outra publicação, pela valorização do formato artigo acadêmico nas Ciências Sociais brasileiras e pela implantação de uma nova cultura acadêmica em nosso país, que ao longo do tempo tornou-se hegemônica. Tal mudança tem no seu fulcro a adoção de uma prática que altera radicalmente o processo de validação do conhecimento científico e que inclusive distingue fundamentalmente o artigo do livro e do capítulo de livro: a revisão por pares duplamente cega. Mesmo nos dias de hoje a publicação de um livro acadêmico no Brasil depende basicamente da capacidade do autor de levantar recursos financeiros e de fazer contatos com editoras $^{1}$. Algo similar acontecia, e ainda acontece, com os periódicos nos quais a escolha dos artigos a serem publicados depende fundamentalmente do editor. Assim como no caso da publicação de livros, esses periódicos se fiam em um sistema aristocrático de validação do conhecimento: a autoridade de declarar se tal ou qual trabalho tem qualidade para ser publicado resta na virtude intelectual do editor ou grupo de editores. Mesmo quando esse editor lança mão da opinião de terceiros, que sejam especialistas, o faz de maneira discricionária, preservando sua autoridade sobre a escolha.

Na revisão por pares duplamente cega são os revisores que decidem chancelar ou não a qualidade da contribuição. Ou seja, a autoridade de validação é transferida do editor para a comunidade científica. Diferentemente do modelo aristocrático, esse é um modelo democrático e verdadeiramente pragmatista, à maneira como o próprio Kuhn imaginou a produção científica: os critérios de validação do conhecimento produzido são dados pelos próprios praticantes da ciência. Ao invés de um editor que pretende exercer autoridade acadêmica a partir de suas supostas qualidades intelectuais e de sua capacidade de constituir um círculo de amizades e contatos, o modelo da revisão por pares duplamente cega se baseia em uma comunidade de autores que são ao mesmo tempo revisores.

A DADOS foi a primeira revista acadêmica de Ciências Sociais do país a adotar, particularmente a partir de 1976, com a entrada de Charles Pessanha na editoria, a revisão por pares duplamente cega de maneira definitiva e sistemática. Tal procedimento encontrou grande resistência da comunidade acadêmica. Hoje, 40 anos depois, é o único modelo aceito pela Coordenação de Aperfeiçoamento de Pessoal de Nível Superior (CAPES) para o funcionamento dos periódicos, pelo menos na 
área de Ciência Política. Sempre preocupado com o aprimoramento dos procedimentos de editoria científica, Pessanha trabalhou com afinco na inclusão da DADOS nas principais bases indexadoras mundiais (inclusive o Institute for Scientific Information - Thomson Reuters), algo também pioneiro no país. Para um panorama mais detalhado da trajetória da DADOS, ver o artigo de Charles Pessanha e a apresentação de Breno Bringel a este número especial dos 50 anos.

Neste texto utilizamos exatamente o artigo acadêmico da DADOS como unidade de análise do perfil e dinâmica da produção da revista nos últimos 50 anos. É razoável supor, também, que ao fazer isso estaremos observando boa parte da produção das Ciências Sociais brasileiras devido ao continuado protagonismo da revista ao longo de sua história. Na verdade, o uso de artigos como proxy do estudo da ciência, antes praticado preferencialmente pelas ciências naturais, é cada vez mais corrente nas Ciências Sociais brasileiras e também mundo afora.

O que se segue está dividido em seis seções. Na primeira, fazemos uma breve discussão sobre os balanços bibliométricos feitos para as Ciências Sociais brasileiras, destacando seus potenciais e limites. A segunda discute a metodologia utilizada para compilar e analisar os artigos que DADOS publicou nessas últimas cinco décadas. Em seguida, passamos para a exposição dos dados mais gerais da revista, como número de artigos publicados, perfil dos autores e dos citados. A quarta seção utiliza a análise de cocitações para estabelecer os agrupamentos temáticos e disciplinares das referências mais recorrentes na revista. Na seção seguinte, com a finalidade de robustecer e aprofundar a análise aplicamos outra técnica, a modelagem de tópicos, para estabelecer os temas mais recorrentes no periódico. Na sexta e última parte refletimos sobre os resultados do trabalho tendo como parâmetro esforços similares.

\section{BALANÇOS BIBLIOMÉTRICOS DAS CIÊNCIAS SOCIAIS}

A expansão nas últimas décadas da produção em Ciências Sociais torna cada vez mais complexa a tarefa de produzir balanços bibliográficos da área. Paradoxalmente, quanto mais abundante a produção de um ramo da ciência, mais necessários são esses trabalhos de síntese e de organização. A institucionalização dos periódicos acadêmicos que acompanhou essa expansão transformou o artigo no principal formato de comunicação científica, como já dissemos anteriormente, e isso teve 
um efeito multiplicador. Bem mais breves que livros, os artigos são mais numerosos e especializados, o que coloca desafios metodológicos específicos às revisões temáticas ou disciplinares.

Por outro lado, o rápido avanço tecnológico permitiu que a comunicação científica se transferisse crescentemente do papel para os computadores e bancos de dados da internet. Isso disponibiliza, entre outras coisas, enormes bases de textos e metatextos que podem, por seu turno, ser analisadas por meio de técnicas bibliométricas computacionais. Grosso modo, é possível definir a bibliometria como qualquer análise quantitativa de um determinado conjunto de textos (OECD, 2013:203). O cálculo do fator de impacto de um periódico talvez seja o emprego mais conhecido de técnicas bibliométricas nos dias de hoje e, certamente um dos mais antigos, pois começou a ser empregado já em 1975 (Garfield, 1998). A despeito das críticas endereçadas ao uso indiscriminado e possíveis vieses do fator de impacto (Editorial, 2016, 2015; Moustafa, 2015; Brembs, Button e Munafò, 2013; Greenberg, 2009) sua utilização continua a crescer no âmbito universitário (Butler e McAllister, 2009; Russell, 2009; Weale, 2009).

Originalmente usadas para o cálculo do fator de impacto, as técnicas bibliométricas tornaram-se a ferramenta preferida da Cienciometria e são hoje empregadas para múltiplas finalidades, como avaliar o rendimento individual de pesquisadores (Hirsch, 2005), a produção de instituições de variadas dimensões, como departamentos (Hix, 2004), programas e universidades (Butler e McAllister, 2009), o perfil da produção de uma disciplina em um determinado contexto nacional (Alfaro Redondo e Vargas Cullell, 2005; Benoit e Marsh, 2009) ou regional (Altman, 2006), a desigualdade de gênero nas profissões acadêmicas (Rocha Carpiuc, 2016) etc. No Brasil há um grupo ativo de pesquisadores que utilizam tais técnicas para estudar a produção científica nacional (Mugnaini, Jannuzzi e Quoniam, 2004; Digiampietri et al., 2012). Outro exemplo importante da penetração de técnicas de análise de cocitações é a avaliação dos programas de pós-graduação feita pela CAPES, que tem como elemento central a publicação de artigos científicos em periódicos classificados segundo seu fator de impacto, entre outros critérios ${ }^{2}$.

Seguindo essa tendência internacional, os estudos bibliométricos das Ciências Sociais brasileiras têm se multiplicado nos últimos anos. Dentre os pioneiros da área, merece destaque a tese de doutorado de 
Glaucia Villas Bôas, defendida em 1992, mas publicada em livro apenas em 2007, na qual a autora pretende determinar a "vocação" dos livros em Ciências Sociais publicados entre 1945 e 1966, mormente a partir da definição de seu temário (Villas Bôas, 2007). O trabalho é digno de nota não apenas pelo seu pioneirismo, mas por inventariar e catalogar dados de 872 títulos disponíveis na Biblioteca Nacional. Dentre suas descobertas formais, vale destacar a preponderância das publicações em História no período ${ }^{3}$ e uma esperada concentração dos trabalhos no eixo Rio-São Paulo. Villas Bôas também identifica uma íntima ligação entre os temas que eram foco das Ciências Sociais nesse momento e os problemas sociais, econômicos e culturais que estavam na agenda política do país (idem). O trabalho de Villas Bôas, contudo, não utilizou técnicas mais complexas de análise de conteúdo, dedicando-se basicamente à apresentação de dados gerais sobre o perfil dos livros publicados.

Outro trabalho bibliométrico pioneiro foi feito por Nelson do Valle Silva (1999), que já utilizou como unidade de análise artigos acadêmicos para determinar o emprego de diferentes metodologias na produção da época. Limitou-se, contudo, aos artigos publicados pela Revista Brasileira de Ciências Sociais (RBCS), escolha que justificou por tratar-se de publicação da Associação Nacional de Pós-Graduação e Pesquisa em Ciências Sociais (Anpocs). Segundo o autor, por essa razão a revista seria "a que melhor expressa a produção acadêmica dominante" (Valle Silva, 1999). Valle Silva então conseguiu compor uma base de 308 artigos, produzidos ao longo dos 13 anos de existência da revista à época em que a pesquisa foi feita. Tal período, contudo, corresponde somente a um terço da vida de DADOS, que vamos examinar aqui em sua integralidade. Ademais, é questionável a premissa de que a RBCS melhor representa a produção da área por pertencer à Anpocs. Por fim, Valle Silva afirma que "o exame das demais publicações indexadas, tais como a DADOS ou a Lua Nova, produzem um quadro muito semelhante" ao que ele encontrou na RBCS: uso pouco frequente de metodologias quantitativas. Infelizmente não poderemos testar essa hipótese de semelhança neste artigo, mas trabalho anterior feito por nós indica que o perfil disciplinar destas revistas é bem diferente (Feres Júnior, Campos e Assumpção, 2016) - claro que essa diferença pode (e deve) ser atribuída à distância temporal entre a contribuição de Valle Silva e a nossa.

Um avanço no aspecto metodológico encontra-se na pesquisa de doutorado de Manuel Palácios Cunha Melo, intitulada As Ciências Sociais 
no Brasil Contemporâneo (1997), defendida no antigo Instituto Universitário de Pesquisas do Rio de Janeiro (IUPERJ), e que serviu de base para artigo subsequente publicado no volume 41 da revista DADOS sobre o perfil das teses de doutorado defendidas nas Ciências Sociais entre novembro de 1992 e maio de 1993 (Werneck Vianna et al., 1998). O artigo traz estatísticas sobre o perfil dos doutorados no período (origem regional e institucional, perfil social, área de atuação etc.), bem como o tema das teses e suas orientações metodológicas gerais. Dentre os resultados ressaltados pelos autores, merece destaque a contribuição do antigo IUPERJ (atual Instituto de Estudos Sociais e Políticos da Universidade do Estado do Rio de Janeiro - IESP-UERJ) na formação de doutores, responsável por quase metade das teses defendidas no período; a predominância de teses baseadas em fontes documentais e abordagem histórica; e a concentração em temas como "cultura", "estudos da religião e das igrejas", "estudos indígenas", "estudos agrários", "sindicatos e operários", "outras sociedades", "atitudes, movimentos e ideologias políticas", "políticas públicas", "estudos de gênero", "pensamento brasileiro" e "ciência social" (Werneck Vianna et al., 1998). Embora a pesquisa não contemple um corte histórico amplo, os autores fazem questão de enfatizar que seus dados corroboram um tipo de perfil das Ciências Sociais brasileiras, própria de contextos de modernização tardia e conservadora, em que "à intelligentsia" caberia a explicação a posteriori das mudanças já ocorridas (idem). Voltaremos a esse ponto no fim do texto, mas vale adiantar que os dados aqui apresentados permitem avaliar, com mais rigor, a relação dos artigos publicados em DADOS com as mudanças no contexto político brasileiro.

Em sua tese, publicada posteriormente em 1999, Melo amplia a análise de dados mais sistemáticos para além das estatísticas descritivas. Utilizando-se basicamente da técnica de Análise de Correspondências Simples, tenta produzir uma cartografia das teses brasileiras, estabelecendo as relações existentes entre determinadas temáticas, disciplinas e as referências citadas por elas. No que concerne às referências bibliográficas, o livro detecta a importância de Pierre Bourdieu, autor mais citado no período, seguido de Max Weber e Karl Marx, respectivamente (Melo, 1999). Ao analisar a relação mútua das citações em cada trabalho (cocitações), Melo aponta para duas grandes linhagens epistêmicas: uma, mais centrada em autores da Sociologia Política, e outra, focada em autores mais próprios da Antropologia, indicando menor separação epistêmica entre Sociologia e Ciência Política na primeira, e 
relativamente maior especialização bibliográfica na segunda (ibidem:133).

A contribuição de Melo deve ser avaliada por suas virtudes, mas também por suas deficiências. Uma delas é o uso de teses de doutorado como proxy da produção geral das Ciências Sociais. Artigos científicos são bem mais apropriados para cumprir esse papel. Além do que já foi dito acima sobre a importância dos artigos, devemos atentar para o fato de que as teses são somente o trabalho de entrada na vida acadêmica profissional, e que muitos doutores não seguem a carreira. Comparativamente, os artigos são produzidos quase que exclusivamente por profissionais acadêmicos em plena atividade. Outro ponto a ser relativizado é a já mitológica liderança de Pierre Bourdieu na lista dos mais citados. Como nossos resultados mostrarão, tal dado deve ser contextualizado.

A Ciência Política tem sido a área na qual mais se realizaram estudos bibliométricos, muitos deles já utilizando artigos como unidade de análise. Um dos primeiros exemplos é o trabalho de Sérgio Augusto Ferraz, que tem por objetivo avaliar o lugar da teoria política normativa no conjunto da produção de Ciência Política (Ferraz, 2004). O autor inclui em sua análise não somente livros, artigos, teses e dissertações, mas também trabalhos apresentados em encontros da Anpocs e da Associação Brasileira de Ciência Política (ABCP). Tentando fazer avaliação semelhante para a subárea de política comparada, Maria Helena Santos e Marcelo Coutinho analisaram 955 teses defendidas entre 1985 e 2000 (Santos e Coutinho, 2000).

Em artigo que faz um balanço da evolução da área de Ciência Política e um raio X de seu estado atual, André Marenco usa como proxy exclusivamente artigos publicados em revistas qualificadas como A1 ou A2 pela CAPES (Marenco, 2015). Marenco ainda publicou um estudo mais recente no qual opta por analisar somente a produção da DADOS para fazer um balanço histórico e temático da Ciência Política no Brasil, justificando a escolha pelo fato de que "apenas Dados (1966) possui uma existência editorial que compreende todo o período de existência da ciência política brasileira" (2016:153). O autor ainda acrescenta:

Desde a introdução do sistema de classificação Qualis/Capes, Dados foi ranqueada como $1 \mathrm{Ae}$, posteriormente A1, os estratos mais elevados da hierarquia, permitindo inferir-se que as publicações aqui analisadas 
correspondem à parte da produção mais qualificada da ciência política brasileira (idem).

Há também os trabalhos da dupla Jairo Nicolau e Lilian Oliveira, que utilizam exclusivamente a análise de artigos para traçar perfis de participação das subáreas da Ciência Política na produção e o uso de metodologias (Oliveira e Nicolau, 2014). Infelizmente, a seleção das revistas estudadas é mal justificada, o que invalida em parte as conclusões que os autores pretendem tirar sobre a área como um todo, como já mostramos em outro momento. Por exemplo, eles não incluem na base de textos as revistas Lua Nova e Revista de Sociologia e Política - tradicionalmente fortes na subárea de teoria - para então concluírem que a presença de artigos de teoria na Ciência Política brasileira é exígua e que, por outro lado, há uma grande influência da pesquisa quantitativa (idem, 2014).

Já a contribuição de Francisco Mata Machado Tavares e Ian Caetano de Oliveira é peculiar, pois classifica a produção de artigos da Ciência Política segundo alegorias que melhor sintetizariam a maneira como concebem a política. São elas: "Fogo no pneu", "Reunião de condomínio", "Cafeteria" e "Gincana". A política como "fogo no pneu", nas palavras dos próprios autores, "se dedica a protestos, sublevações, insurgências, revoluções e toda prática de agonismo político" (Tavares e Oliveira, 2016:28). Já a "reunião de condomínio" corresponde aos estudos da participação política. A alegoria da "cafeteria" é reservada aos trabalhos que enfocam os aspectos comunicativos e deliberativos da política. E, por fim, a alegoria da "gincana" aplica-se aos enfoques neoinstitucionalistas e da escolha racional, que representam a política com jogo de interesses. Apesar da inventividade dessa tipologia, vale mencionar que os autores praticamente não fornecem pistas de como os textos foram encaixados em cada uma das abordagens. Ademais, a definição do tipo "fogo no pneu" é a mais ambígua de todas, haja vista o fato de não ficar explícito em que medida ela reflete uma abordagem maquiaveliana da política ou um foco na política feita para além das instituições. Não surpreende, portanto, que depois de classificarem os artigos de todas as revistas brasileiras qualificadas como A1 e A2 pela área de Ciência Política da CAPES, concluem os autores, em tom de crítica e de maneira demasiadamente breve, que há muito pouco "fogo no pneu" na Ciência Política brasileira (ibidem:38). Tal conclusão já estava prevista, de certo modo, no desenho mesmo da tipologia. 
A contribuição de Fernando Leite é até hoje a mais ambiciosa no campo da aplicação de técnicas bibliométricas para o estudo da Ciência Política brasileira. A tese de Leite tem como tema a consolidação da Ciência Política brasileira por via da dupla autonomização institucional e disciplinar. Para examinar o perfil disciplinar o autor analisa todos os artigos de Ciência Política publicados em periódicos com conceito A1 (DADOS, Opinião Pública - OP, RBCS) e A2 (Brazilian Political Science Review, Lua Nova, Revista de Sociologia \& Política e Saúde Pública), no período de 2004 a 2008 (Leite, 2015). Leite publicou alguns artigos explorando tópicos específicos já presentes na tese, como o impacto da CAPES e de seu Qualis na normatização da produção na área (Leite e Codato, 2013) e a estruturação hierárquica dos temas e abordagens refletida na produção (Leite, 2010; 2016).

Mesmo que trabalhando com material da mesma natureza, artigos acadêmicos, o método escolhido por Leite é bem diferente do indutivo proposto por nós aqui. Leite submete os artigos a um pesado processo hermenêutico de classificação em múltiplas variáveis: áreas temáticas, abordagens, natureza do objeto, tradições intelectuais, tradições disciplinares, visões de disciplina, estilos cognitivos, tradições intelectuais, amplitude do argumento e escopo do argumento. O método empregado em nosso presente estudo, como veremos a seguir, deixa a interpretação somente para o final da análise. Acreditamos que há uma significativa diferença entre submeter dados crus ou interpretados à análise quantitativa, discutiremos esse aspecto na conclusão do texto.

\section{METODOLOGIA}

O corpus da pesquisa foi composto em duas etapas. Em um primeiro momento, compilamos todos os textos publicados pela DADOS de 1996 até 2015. Essa compilação foi facilitada pelo fato de esses artigos estarem indexados na plataforma Scielo.br, portal virtual que disponibiliza os textos das principais revistas acadêmicas brasileiras. Aproveitando o fato de o portal identificar características indexadoras de cada artigo em uma linguagem padronizada ${ }^{4}$, desenvolvemos um algoritmo de raspagem de dados que sistematizou informações como título, resumo, nome do autor, referências citadas etc. em um banco de dados. Em um segundo momento, adicionamos ao mesmo banco as informações dos textos publicados na DADOS entre 1966 e 1995.

As informações desse conjunto foram compiladas por uma equipe de pesquisadores que preencheu manualmente alguns campos do banco, 
tarefa bastante trabalhosa, uma vez que os padrões de citações mudaram ao longo do tempo e das transformações do formato da revista. Só para darmos um exemplo das dificuldades de se preparar tal base de dados, por décadas os artigos eram publicados sem lista de referências bibliográficas ao final. Todas as citações estavam em notas de rodapé e precisaram ser copiadas, uma a uma, de cópia digitalizada do texto cujos caracteres foram previamente reconhecidos. Outro problema tem a ver com as diferentes grafias dos nomes dos autores e dos citados. Um mesmo acadêmico pode assinar trabalhos diferentes com nomes levemente distintos (exemplo, Fulano de Tal, Fulano D. Tal ou Fulano Detal), e o mesmo se aplica ao formato ou estilo dos citados ou ao modo como o material bibliográfico é referido. Por conta disso, nossa base teve de ser submetida a um rigoroso trabalho de pósprocessamento. Contudo, tendo em vista algumas ausências no material histórico e a natureza mesma desses dados, há uma grande chance de que alguns casos e variáveis apresentem problemas. Estes serão certamente identificados e corrigidos com o tempo, à medida que a pesquisa avançar. De todo modo, as eventuais deficiências dos dados não impedem que tomemos o corpus como um retrato geral das características editoriais do periódico.

A análise que se segue considera apenas os artigos acadêmicos publicados na revista e, portanto, eliminou todos os textos que não tinham propriamente um formato de artigo acadêmico (notas de pesquisa, cronologias, obituários, bibliografias comentadas e resenhas), com referências à literatura especializada ou aqueles com dimensões muito pequenas. Vale mencionar também que a quantidade de artigos publicados pela revista DADOS entre 1970 e 1975 foi menor do que a média do quinquênio anterior e posterior, dado que deve matizar a validade das inferências para esse período. Excluímos também alguns textos publicados no número 3 do volume 37 (1994). Trata-se de edição especial dedicada a uma pesquisa feita por Luiz Werneck Vianna, Maria Alice Rezende de Carvalho e Manuel Palácios Cunha Melo sobre o perfil dos estudantes de graduação em Ciências Sociais, entre 1992 e 1993. Tendo em vista que os textos neste número, com a exceção de um, não tinham o formato de artigo acadêmico, se aproximando mais de capítulos de um grande relatório, optamos por não os incluir na análise.

Nas últimas seções deste artigo buscamos delinear o perfil da DADOS ao longo de sua história a partir da combinação de diferentes técnicas de análise de grandes corpora linguísticos, mormente a Análise de Cocitações e Modelagem de Tópicos. Muito utilizada pela Cienciome- 
tria para identificar redes de cooperação acadêmica, a Análise de Cocitações vem sendo empregada com o objetivo de mapear determinados campos científicos (Melo, 1999; Bourdieu, 1988; Feres Jr., Campos e Assumpção, 2016; Leite, 2015). Grosso modo, ela parte da premissa que a co-ocorrência de referências bibliográficas em artigos acadêmicos indica nichos temáticos ou abordagens comuns. Para traduzir essas redes de cocitação em representações gráficas, utilizamos aqui a Análise de Correspondência Simples (ACS), técnica que permite expor em um mapa bidimensional as co-ocorrências relativas entre as categorias de duas variáveis. A partir do cruzamento entre duas variáveis categoriais, a ACS produz uma ilustração em que os valores que mais co-ocorrem são plotados mais próximos um do outro, enquanto os valores que menos aparecem juntos nos artigos aparecem distantes um do outro ${ }^{5}$. Em termos analíticos, a ACS pode ser entendida como um "campo magnético" (Bourdieu, 2007), no qual os elementos se atraem na razão direta de sua co-ocorrência na base de textos.

Para ajudar a identificar os temas recorrentes nos textos do corpus, empregamos um algoritmo de Modelagem de Tópicos (Topic Modeling). A partir das palavras contidas nos resumos em inglês (abstracts) dos artigos da revista ${ }^{6}$, esse algoritmo identifica os textos lexicamente semelhantes, permitindo que se avalie em que medida os termos mais recorrentes neles indicam um tema específico. Como resultado, ele gera uma lista de possíveis tópicos acompanhada das respectivas palavras mais recorrentes em cada um, lista essa que funciona como um guia de classificação temática dos textos.

\section{RESULTADOS GERAIS}

Entre 1966 e 2015, DADOS publicou 895 textos classificados por nós como artigos acadêmicos ${ }^{7}$, segundo os critérios explicitados anteriormente. Eles estão distribuídos no tempo conforme o gráfico a seguir. Desde o período entre 1986 e 1990, a revista vem incrementando de modo linear a quantidade de artigos publicados, passando de 76 textos entre 1986 e 1990 para 154 entre 2011 e 2015.

No total, 700 autores diferentes publicaram na revista no período analisado, o que dá uma média 1,28 artigos por autor. Isso indica o predomínio de textos assinados por apenas um acadêmico no corpus. Embora a coautoria seja comum nas ciências exatas, ela costuma ser mais rara nas ciências humanas (Soares, Souza e Moura, 2010). Esse fato reflete algumas das características dessa grande área, em que os esforços 


\section{Gráfico 1}

\section{Distribuição dos Artigos Publicados em DADOS por Quinquênio}

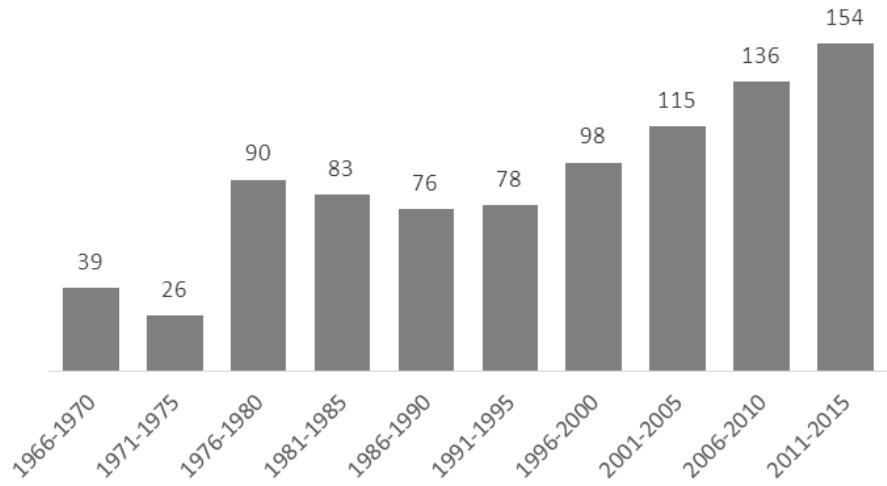

Fonte: Os autores, a partir de informações da revista DADOS.

coletivos de pesquisa, como laboratórios, e o financiamento de grandes projetos ainda são raros, se comparados às pesquisas individuais e publicações solitárias. Dito isso, as Ciências Sociais nos últimos anos têm apresentando taxas crescentes de textos de autoria múltipla, o que talvez reflita mudanças na forma como essa área esteja se organizando. Na DADOS, o percentual de textos assinados por mais de um autor cresceu de forma consistente no período analisado, saindo de $10 \%$ no primeiro quinquênio para 35\% no intervalo entre 2011-2015, como aponta o Gráfico 2.

\section{Gráfico 2}

Percentual de Textos Publicados em DADOS por mais de um Autor/Autora

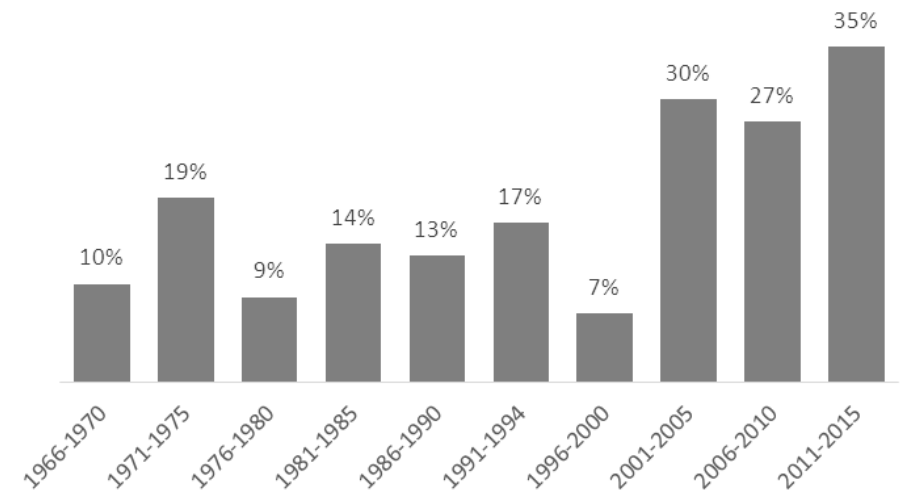

Fonte: Os autores, a partir de informações da revista DADOS. 
Em relação ao sexo dos autores que publicaram na DADOS, há uma preponderância de homens em relação às mulheres. De todos os artigos publicados, $67,4 \%$ foram assinados apenas por homens, enquanto $22,9 \%$ foram assinados apenas por mulheres e $9,7 \%$ por autores de ambos os sexos. Contudo, a prevalência dos homens vem diminuindo gradativamente desde o quinquênio 1996-2000. Nesse período, a proporção de artigos assinados apenas por um ou mais homens foi de $79 \%$, percentual que cai para $58 \%$ no último quinquênio considerado (2011-2015). Isso quer dizer que ao menos $42 \%$ dos textos do período contaram com uma autora mulher. Na verdade, enquanto a participação de homens como único autor caiu ao longo dos anos, particularmente a partir do quinquênio 1996-2000, a participação de mulheres como única autora não demonstrou tendência clara, ficando por todo o período dentro do intervalo de $16 \%$ a $32 \%$. O que explica a queda da participação de homens como autor único é o crescimento de artigos com autores de ambos os sexos, categoria que começa no mesmo quinquênio de 1996-2000 com esquálidos 3\% do total publicado e atinge $16 \%$ no período mais recente.

Dos 700 autores e autoras que publicaram na DADOS nesses 50 anos, Wanderley Guilherme dos Santos, fundador da instituição sede da revista, o antigo IUPERJ (atualmente, IESP-UERJ), foi o autor com maior número de artigos publicados (12 no total). Em seguida, aparecem Simon Schwartzman (11), Bolívar Lamounier, Fabiano Santos, Gláucio Ary Dillon Soares e Olavo Brasil de Lima Júnior (cada um com 10).

\section{Gráfico 3}

Percentual de Textos por Quinquênio de acordo com o Sexo do/a(s) Autor/a(s)

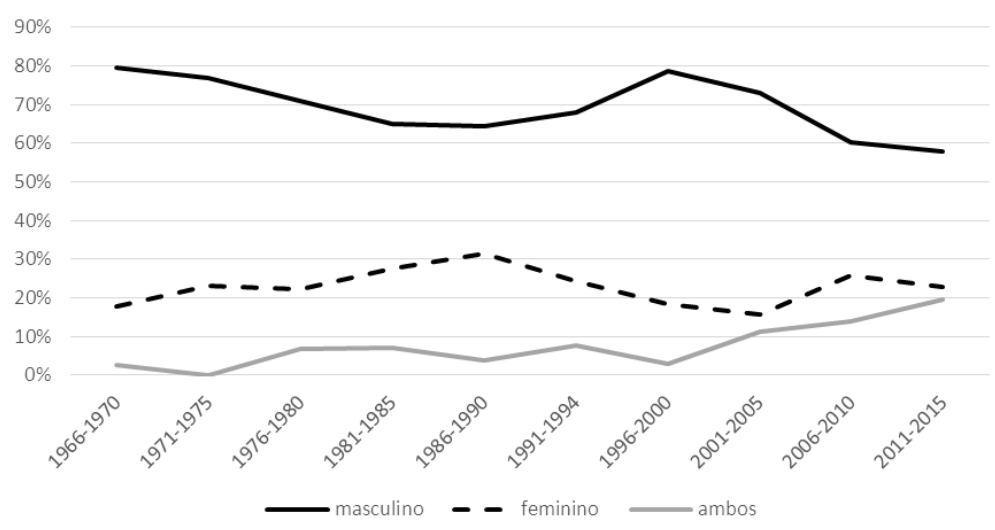

Fonte: Os autores, a partir de informações da revista DADOS. 
Desde já, percebe-se uma preponderância de cientistas políticos na lista, algo que reflete a vocação inicial da revista, voltada para a área (para mais detalhes, ver os artigos de Christian Lynch e André Botelho, publicados nesta coletânea). Por outro lado, há também no topo da lista nomes importantes da Sociologia, como Adalberto Cardoso e José Maurício Domingues (ambos com 9 artigos). Nessa lista, há uma evidente predominância de autores do antigo IUPERJ/IESP-UERJ, nas

\section{Gráfico 4}

Lista de Autores conforme a Quantidade de Artigos Publicados na Revista (mais de cinco)

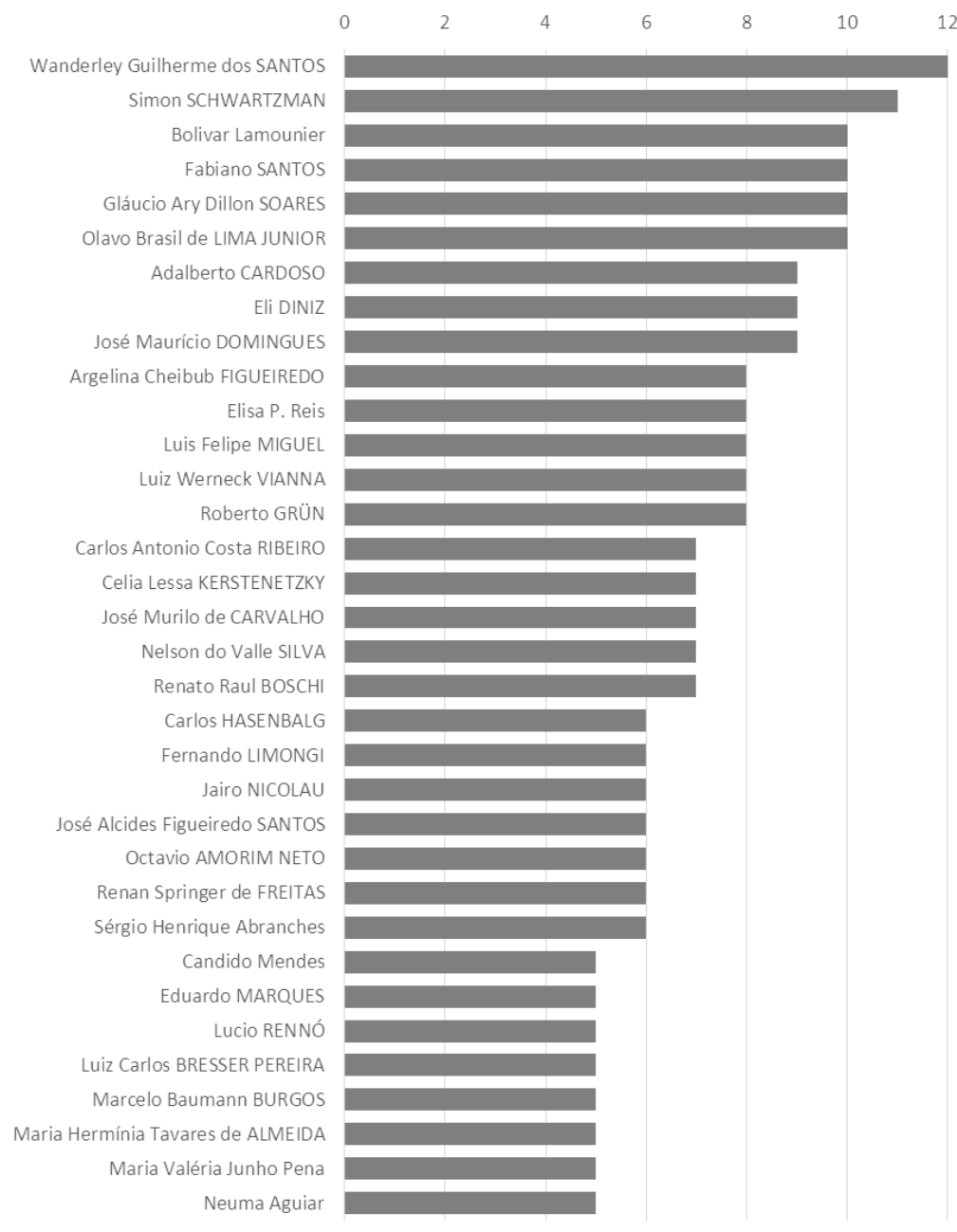

Fonte: Os autores, a partir de informações da revista DADOS. 
páginas da revista. Vale lembrar que a revista funcionou como canal de publicização das pesquisas feitas no IUPERJ e de alguns convidados até meados dos anos 1970, quando ela adotou o sistema de revisão cega por pares. Isso faz com que os pesquisadores da Casa apareçam sobrerrepresentados no corpus como um todo. Outro fator que contribui para isso é a longevidade e produtividade de autores como Wanderley Guilherme, Simon Schwartzman, Bolívar Lamounier e Gláucio Soares, o que, em grande medida, explica essa predominância.

A disciplina de origem dos autores e autoras reitera a orientação editorial da revista, centrada na Ciência Política e na Sociologia. Por diversos motivos, não foi simples encaixar cada um dos 700 autores e autoras em uma disciplina específica das Ciências Sociais: muitos têm uma trajetória multidisciplinar ou construíram uma carreira em uma área distinta daquela em que se graduaram ou pós-graduaram, além dos casos em que simplesmente não foi possível encontrar informações profissionais sobre alguns autores. Para facilitar essa classificação, decidimos, assim, trabalhar apenas com cinco categorias: Ciência Política, Sociologia, Antropologia, não identificada e outras. Autores mais próximos das Relações Internacionais foram somados ao grupo dos cientistas políticos, haja vista o fato de a área ter se autonomizado no Brasil apenas recentemente.

Como é possível perceber pelo Gráfico 5, a maioria dos autores que publicaram na revista em todos os quinquênios foram oriundos da Ciência Política, seguidos de perto pelos sociólogos. Vale notar, porém, que a participação dos artigos de antropólogos e antropólogas cresce de forma constante desde a fundação da revista até se estabilizar em 1980, o que provavelmente refletiu a criação das revistas especializadas da área como Mana e, posteriormente, Horizontes Antropológicos. O único momento em que esse padrão se modifica é entre 1971-1975, mas isso provavelmente reflete a pequena quantidade de textos desse período. No total, $49 \%$ dos textos foram assinados por cientistas políticos, $34 \%$ por sociólogos, $7 \%$ por antropólogos e $14 \%$ por autores de outras áreas. Não conseguimos identificar a pertença profissional de $4 \%$ dos textos do corpus.

No tocante aos autores mais citados nos artigos da revista, Wanderley Guilherme dos Santos também aparece na liderança, sendo expressamente referido em cerca de $16 \%$ de todos os textos publicados desde 1966. Em seguida, aparecem Fernando Henrique Cardoso (13\%), 


\section{Gráfico 5}

Perfil Disciplinar dos Autores e Autoras por Quinquênio

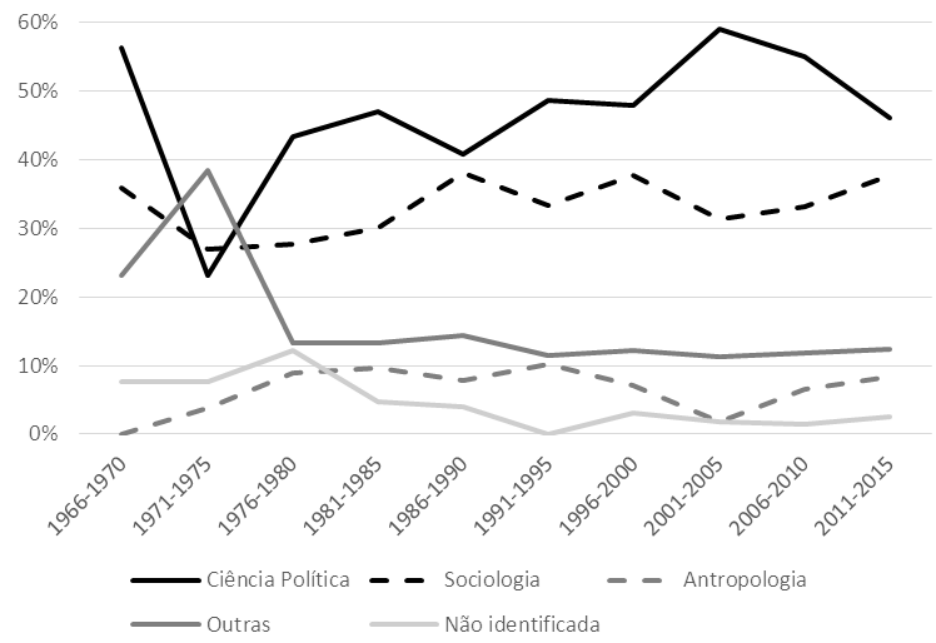

Fonte: Os autores, a partir de informações da revista DADOS.

Max Weber (12\%), Bolívar Lamounier, Argelina Figueiredo e Scott Mainwaring (cerca de 11\%), Pierre Bourdieu e Fernando Limongi (cerca de 10\%). Já há aqui alguns dados interessantes. Primeiro, é de se esperar que um periódico focado em temas políticos durante a maior parte de sua existência tivesse, dentre os autores mais citados em seus artigos, analistas da política nacional. Segundo, essa lista difere substantivamente daquela obtida por Melo (1999) para as teses de doutorado defendidas entre 1992 e 1993 nas três Ciências Sociais, nas quais predominam os autores clássicos da Sociologia como Max Weber, Karl Marx e, sobretudo, Pierre Bourdieu.

Entretanto, é temerário comparar essa lista de citados com outras produzidas para recortes longitudinais distintos. Quando observamos a dinâmica temporal, vemos, por exemplo, que autores como Wanderley Guilherme e Fernando Henrique atingem o auge de citações na década de 1980 e 1990, mas declinam nos últimos anos. Pierre Bourdieu, por seu turno, torna-se o autor mais citado no último quinquênio, o que mostra a proximidade dos textos publicados na DADOS com os demais do campo (Gráfico 7). Isso nos leva a conjecturar que a preponderância de Bourdieu na lista de autores mais citados na tese de Manuel Palácios Melo (1999) reflete, na verdade, um crescimento recente da importância do sociólogo francês. 
50 Anos da Revista DADOS: Uma Análise Bibliométrica do seu Perfil...

\section{Gráfico 6}

Lista de Autores Citados em mais de 5\% dos Artigos do Corpus ${ }^{8}$

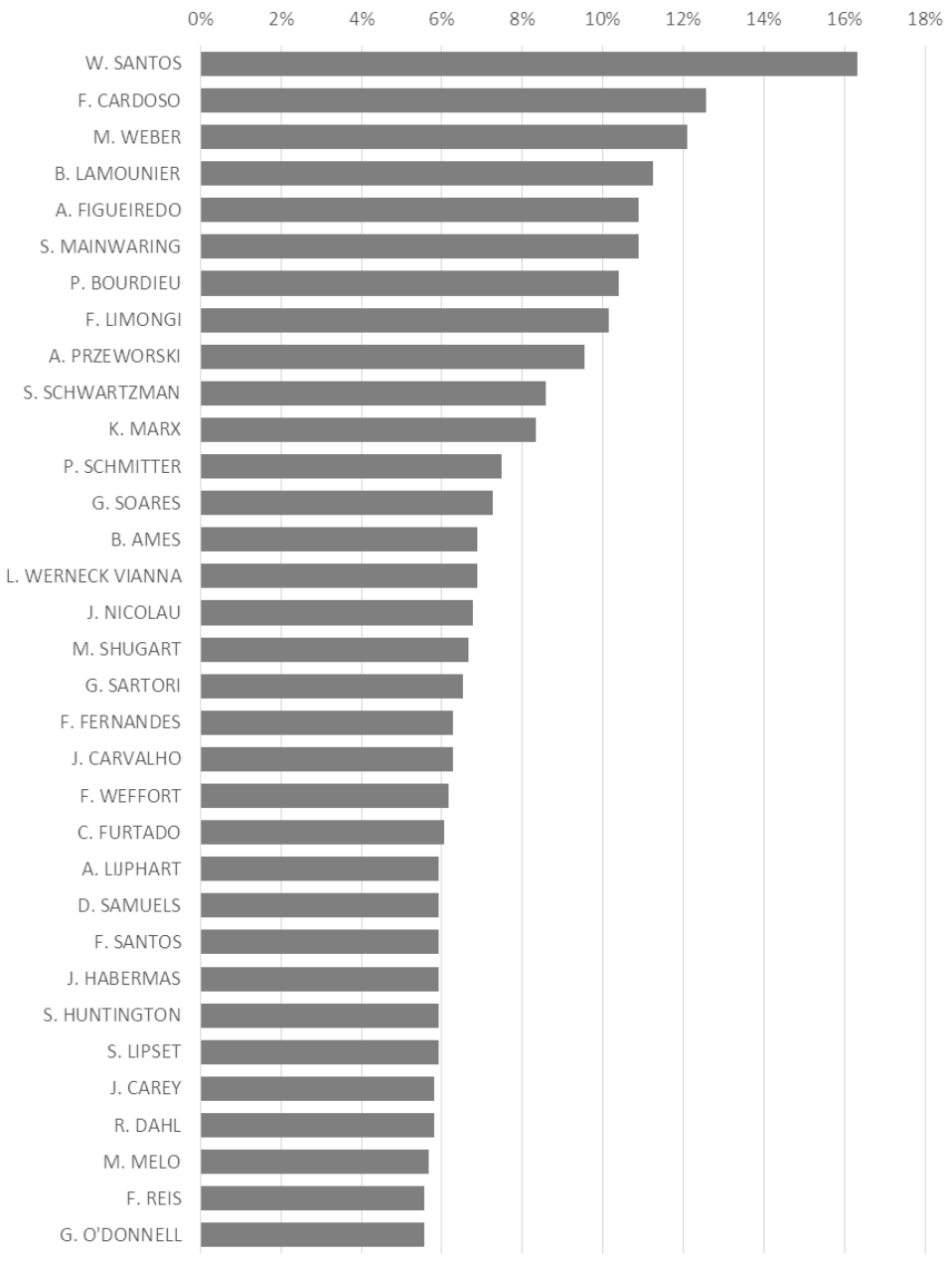

Fonte: Os autores, a partir de informações da revista DADOS.

A Tabela 1 apresenta uma lista dos dez autores mais citados em cada um dos quinquênios. Ela permite perceber, ainda que indiretamente, a expressiva mudança dos objetos de pesquisa e das abordagens disciplinares ao longo do tempo. Nos quatro primeiros quinquênios, predominam os temas do desenvolvimento econômico (Celso Furtado, Hélio Jaguaribe e Fernando Henrique Cardoso) e político (Seymour Lipset, Wanderley Guilherme, Philippe Schmitter). Essa composição muda a partir do quinto quinquênio até o sétimo, com a entrada de au- 


\section{Gráfico 7}

Percentual de Citações de Wanderley Guilherme dos Santos, Fernando Henrique Cardoso e Pierre Bourdieu por Quinquênio

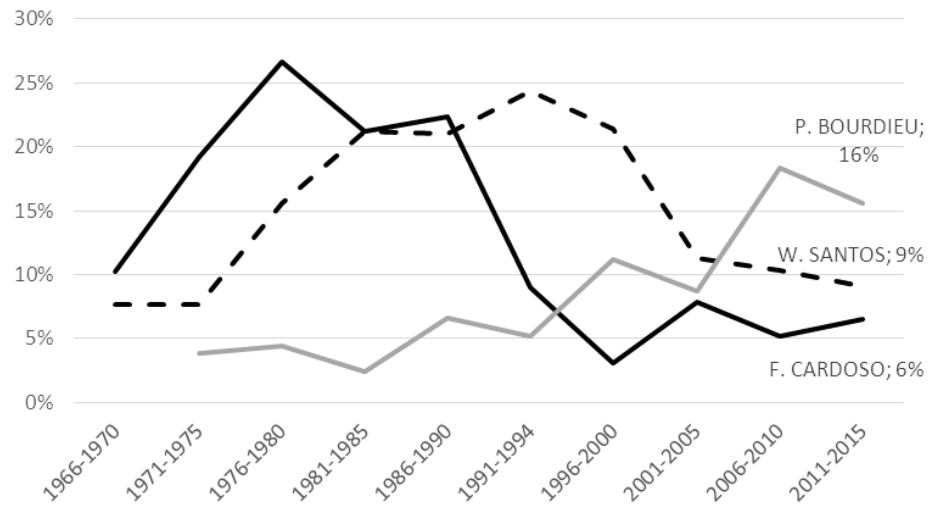

Fonte: Os autores a partir de informações da revista DADOS.

tores mais próprios da literatura da transitologia (Adam Przeworski, Guillermo O'Donnell, Philippe Schmitter) e autores identificados com a abordagem neoinstitucionalista na Ciência Política (Adam Przeworski, Scott Mainwaring, Matthew Shugart, Argelina Figueiredo e Fernando Limongi). Já entre 2006 e 2015, há uma crescente influência de referências mais próprias da teoria social e da filosofia, como o já citado Bourdieu e Michel Foucault.

É interessante notar que, a despeito das diferentes abordagens ao longo dos anos, o tema dominante foi a sociedade brasileira. O desenvolvimento político e econômico discutido era o brasileiro, a transição para a democracia e o funcionamento das instituições democráticas focavam o caso brasileiro. Mesmo os autores estrangeiros que alcançaram o topo da lista, excetuando-se os medalhões clássicos como Marx e Weber, são frequentemente brasilianistas. Somente os dois últimos quinquênios parecem desviar do padrão, quando Pierre Bourdieu, que sobre o Brasil escreveu somente um texto infeliz sobre relações raciais, lidera a lista. Mesmo aí, contudo, as listas são dominadas por autores que têm a democracia como tema, não raro trabalhando dentro da abordagem neoinstitucionalista.

\section{CARTOGRAFIA DAS CITAÇÕES}

Como afirmamos antes, a análise de cocitações pode ser usada para investigar a constituição de redes e linhagens acadêmico-bibliográficas. 
50 Anos da Revista DADOS: Uma Análise Bibliométrica do seu Perfil...

.

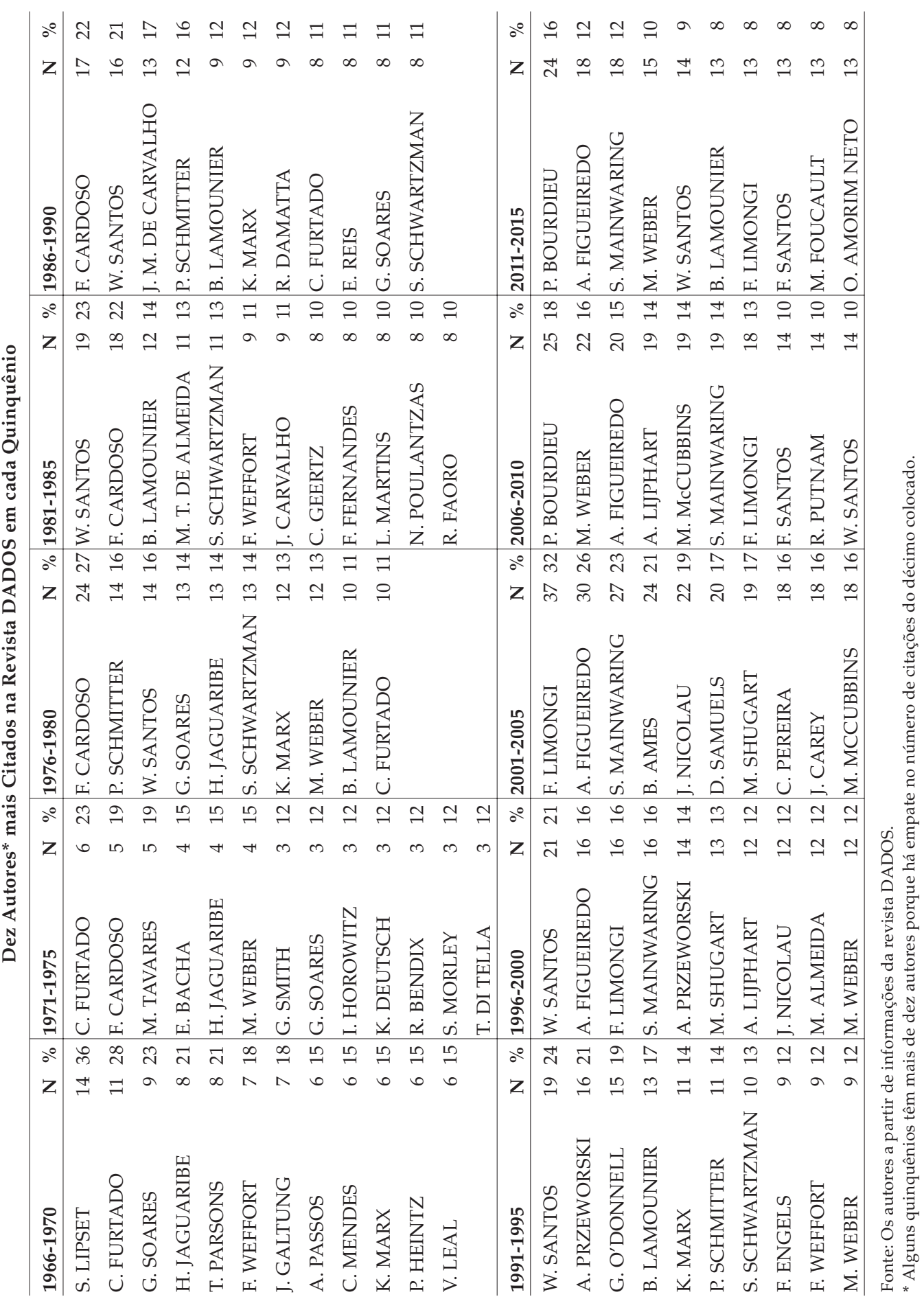

DADOS - Revista de Ciências Sociais, Rio de Janeiro, vol. 60, nº 3, 2017641 
No entanto, seu potencial analítico para as Ciências Sociais e para o estudo do pensamento sociológico ainda está, em grande medida, inexplorado. Nesta seção, utilizamos a análise de cocitações para melhor compreender quais nichos bibliográficos predominaram nesses 50 anos da revista DADOS. Partimos do pressuposto de que referências bibliográficas que costumam ser muito citadas em conjunto podem nos ajudar a identificar núcleos temáticos ou abordagens similares e, consequentemente, delinear as orientações intelectuais e bibliográficas predominantes no periódico. É importante notar que o caminho metodológico proposto aqui evita um problema também enfrentado no âmbito da avaliação, que é o da imposição de autoridade externa ao próprio objeto para validá-lo. Isto é, os trabalhos ensaísticos que até agora pretenderam examinar as configurações do campo das Ciências Sociais sempre se apoiaram na suposta autoridade do autor em determinar quais correntes teóricas e disciplinares de fato existem e qual sua importância relativa.

Como dito na seção sobre a metodologia, utilizamos a Análise de Correspondências para expor em uma representação gráfica a dinâmica das cocitações. Os mapas a seguir podem ser lidos como cartografias das citações, em que autores graficamente mais próximos são frequentemente citados nos mesmos artigos, enquanto autores distantes raramente aparecem em um mesmo texto. Como esse tipo de análise só pode ser feita entre referências muito citadas ${ }^{9}$, optamos por considerar apenas os citados em mais de 1,5\% do corpus, isto é, em mais de 13 artigos. Isso nos levou a uma lista de 243 autores. Mais de $95 \%$ dos textos citam ao menos um desses autores, o que torna os mapas a seguir bastante representativos do corpus total.

A Figura 1 apresenta a Análise de Correspondências entre esses autores mais citados. Para melhorar a visualização do mapa, reproduziremos em seguida alguns recortes que nos permitirão examinar com mais detalhe cada uma de suas áreas. As partes do gráfico geral amplificadas nos recortes estão indicadas por quadrados numerados conforme os respectivos gráficos.

A Figura 1.1 apresenta a parte superior-direita da Figura 1. Nela se encontram referências tradicionais da Antropologia como Marcel Mauss, Claude Lévi-Strauss e Mary Douglas, bem como nomes clássicos da Teoria Sociológica como Erving Goffman, Ernesto Laclau, Niklas Luhmann, Anthony Giddens, Michel Foucault, José Maurício 
50 Anos da Revista DADOS: Uma Análise Bibliométrica do seu Perfil...

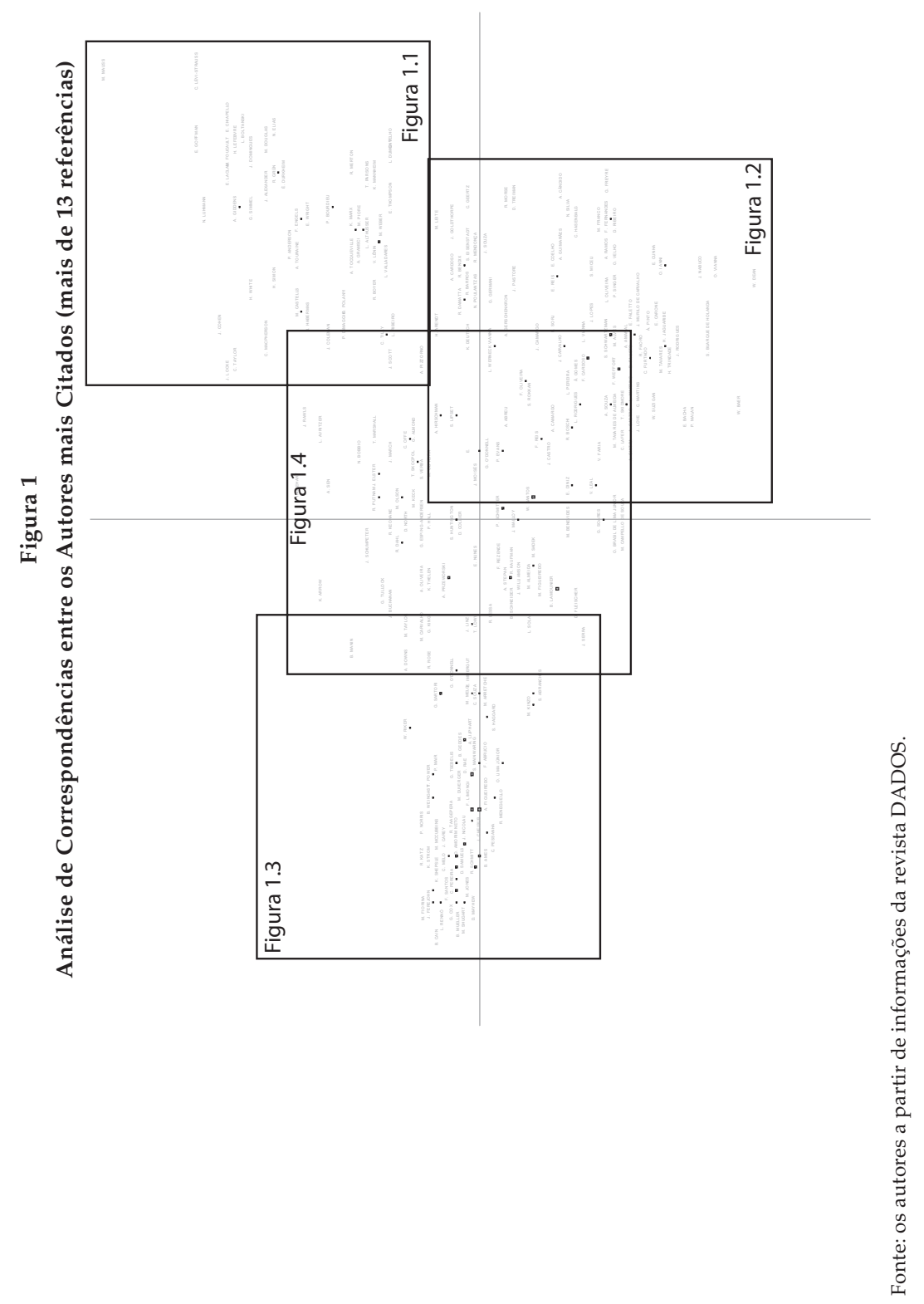

DADOS - Revista de Ciências Sociais, Rio de Janeiro, vol. 60, nº 3, 2017643 
Luiz Augusto Campos, João Feres Júnior e Fernando Guarnieri

Figura 1.1

Análise de Correspondências entre os Autores mais Citados

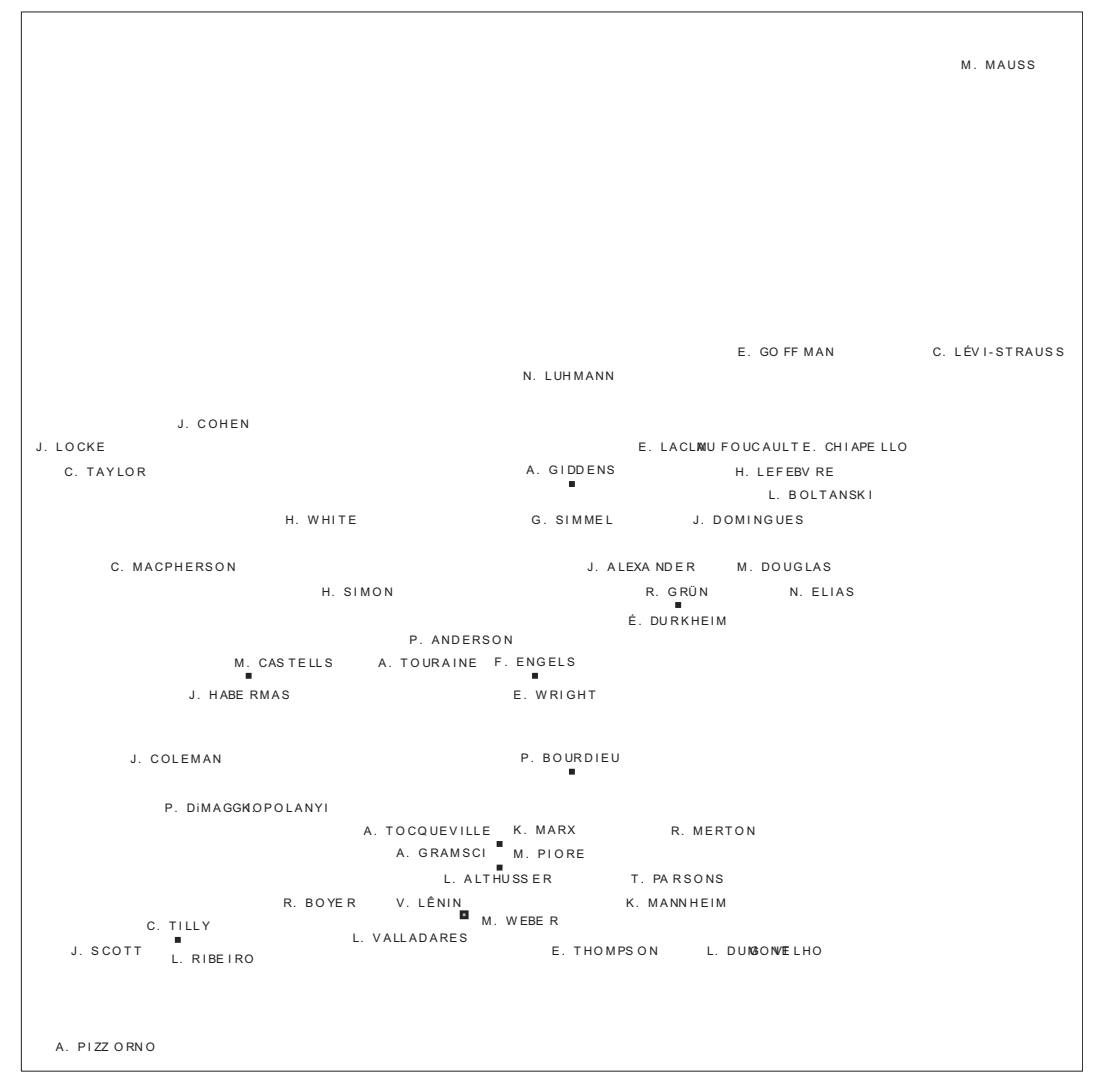

Fonte: Os autores, a partir de informações da revista DADOS.

Domingues, Émile Durkheim, Norbert Elias, Pierre Bourdieu etc. Migrando do canto superior direito em direção à esquerda do mapa, as referências começam a se aproximar da reflexão política, incluindo autores como John Locke, Charles Taylor, C. B. Macpherson. Na metade inferior do quadro aparecem alguns clássicos da reflexão marxista (Gramsci, Althusser, Lênin, Thompson etc.) e o próprio Marx, além de clássicos do pensamento sociológico como Merton, Parsons, Mannheim, Polanyi, Tilly e Tocqueville. Portanto, é possível notar que o quadrante 1.1 concentra as referências da Teoria Sociológica, Política e Antropológica, com destaque para uma maior diversidade de autores e autoras das duas primeiras áreas: 
50 Anos da Revista DADOS: Uma Análise Bibliométrica do seu Perfil...

Figura 1.2

Análise de Correspondências entre os Autores mais Citados

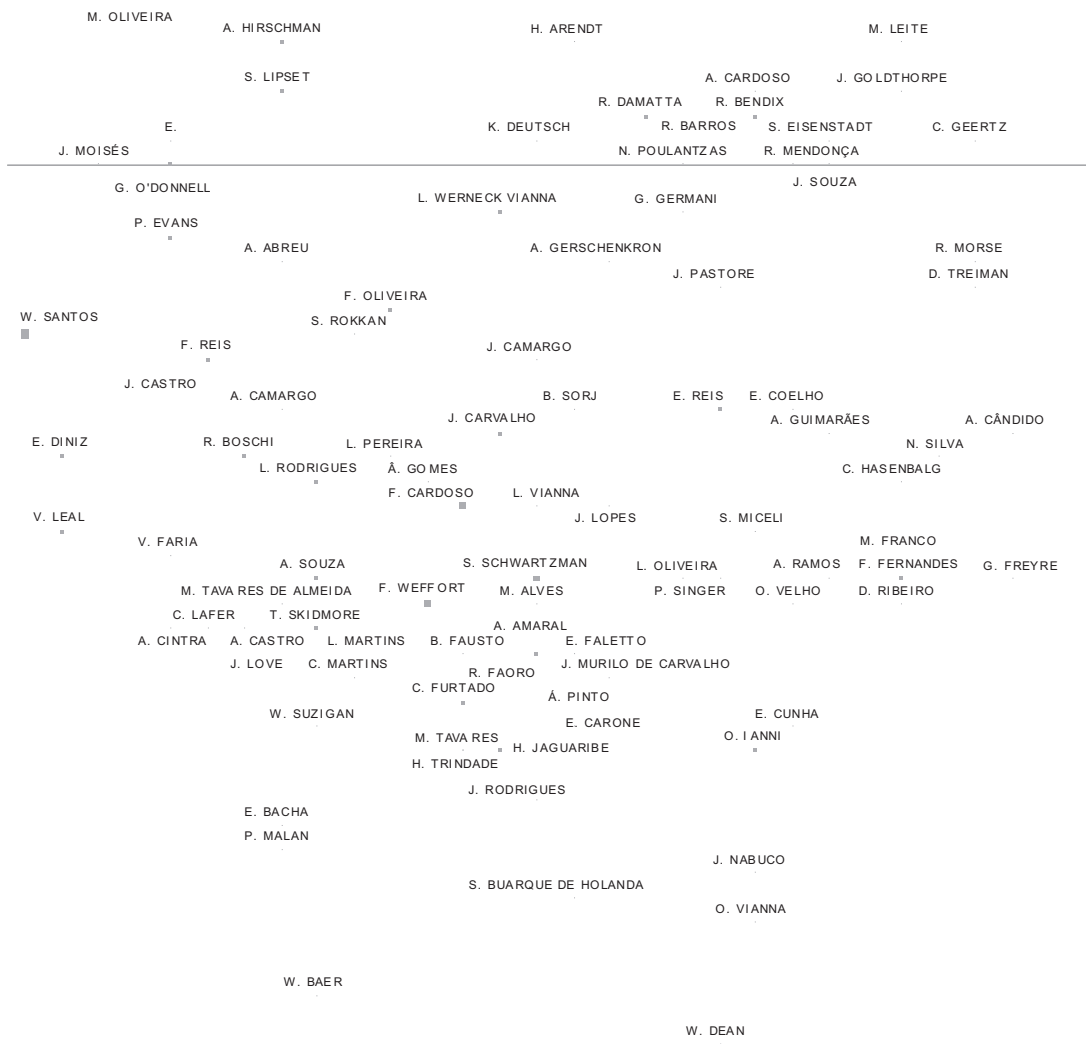

Fonte: Os autores, a partir de informações da revista DADOS.

A Figura 1.2 revela em sua parte superior uma transição dos clássicos das teorias sociológica, política e antropológica para o que se denomina pensamento social e político brasileiro ${ }^{10}$. A mediana da figura coincide quase que perfeitamente com a passagem de um tema para o outro. Na parte central do quadrante identificamos os nomes de Oliveira Vianna, Sérgio Buarque de Holanda, Hélio Jaguaribe, Octavio Ianni, Celso Furtado, José Murilo de Carvalho, Luiz Werneck Vianna, Simon Schwartzman, Otávio Velho, Hélgio Trindade - autores que de alguma maneira estavam envolvidos em debates sobre a "questão nacional", seja no que toca a seus aspectos identitários ou seu desenvolvimento/modernização. À esquerda do recorte da Figura 1.2, ou seja, a cami- 
nho do centro da grande figura há uma zona de transição composta por autores que fazem a ponte entre o caso brasileiro e preocupações disciplinares oriundas da Ciência Política e da Sociologia Política, como Estado, políticas públicas e instituições em geral. Lá estão os nomes de Wanderley Guilherme dos Santos, Fabio Wanderley Reis, Eli Diniz, Maria da Conceição Tavares, Renato Boschi etc.

A Figura 1.3 contém o recorte da parte esquerda do mapa. Nela, aparecem com alta proximidade nomes como Lucio Rennó, Fabiano Santos, Fernando Limongi, Carlos Pereira, Octavio Amorim Neto, Jairo Nicolau, Rachel Meneguello, Robert Katz, David Samuels, José Antônio Cheibub, Matthew Shugart, Fernando Limongi, Argelina Figueiredo, Sergio Abranches, Scott Mainwaring, Maurice Duverger, Celina Souza, Maria D'Alva Kinzo, Marta Arretche etc. Trata-se de autores adeptos do neoinstitucionalismo e dos estudos de instituições políticas (eleições, sistemas partidários etc.).

Por fim, a Figura 1.4 contém o quadrante da parte central do mapa, para onde as três tendências anteriores convergem. Seguindo a lógica do método de análise de correspondências, as referências aqui locali-

Figura 1.3 Análise de Correspondências entre os Autores mais Citados

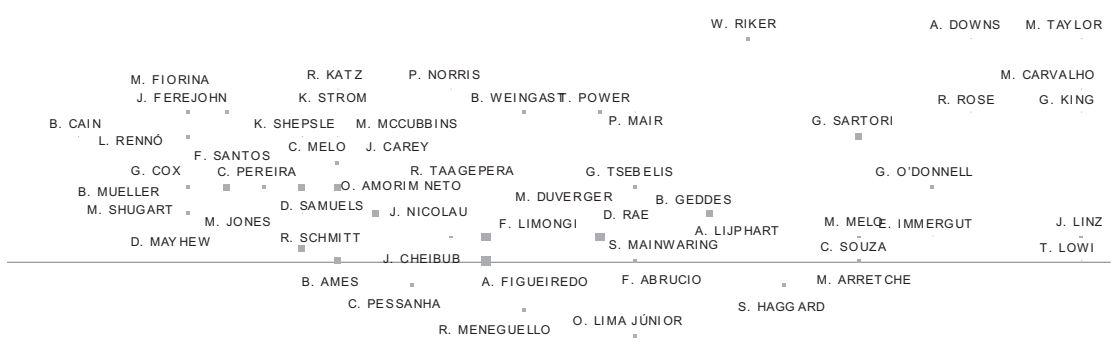


50 Anos da Revista DADOS: Uma Análise Bibliométrica do seu Perfil...

Figura 1.4

Análise de Correspondências entre os Autores mais Citados

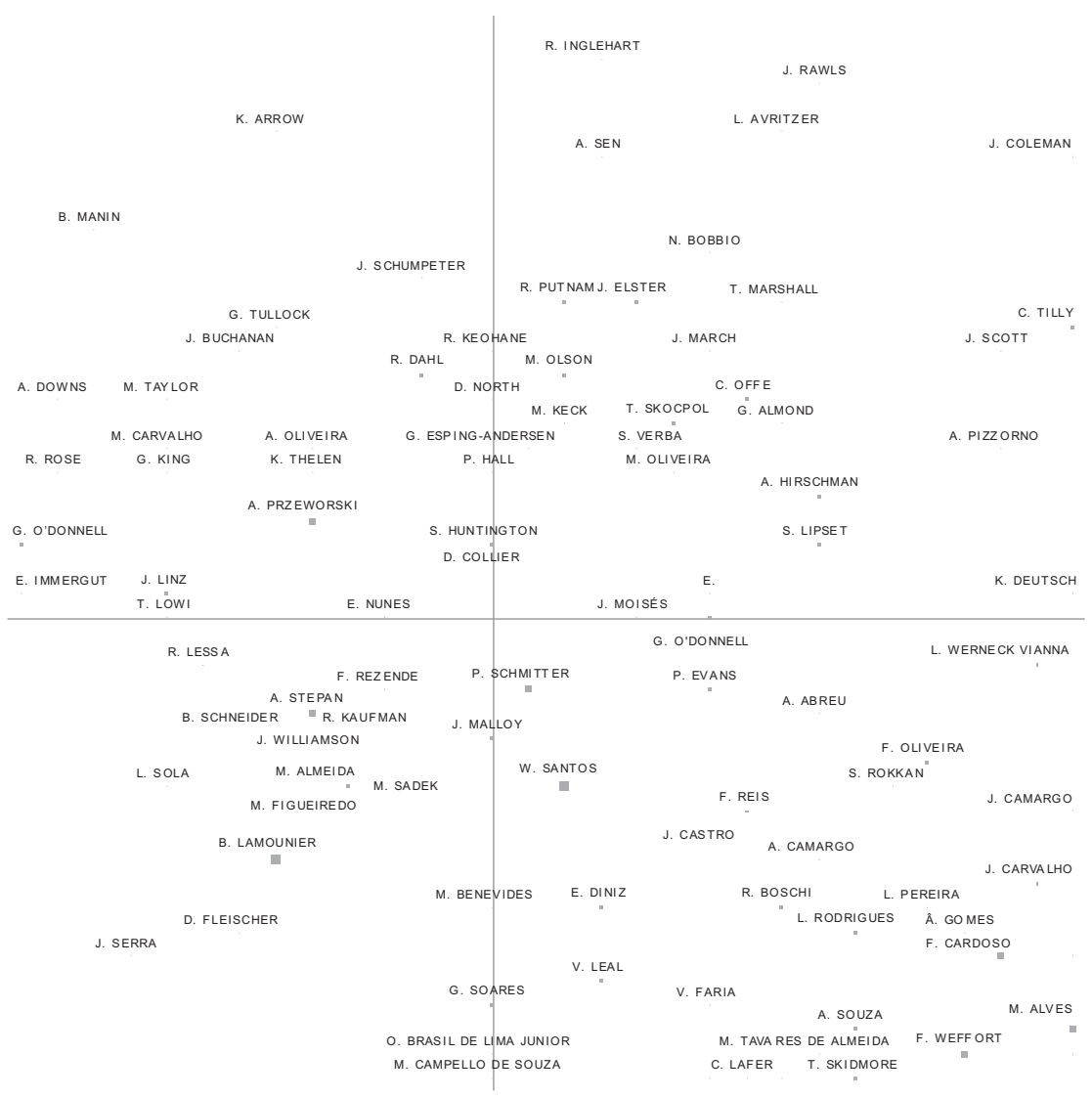

Fonte: Os autores, a partir de informações da revista DADOS.

zadas tendem a ser mais ecléticas, isto é, para além das referências mútuas também citam nomes das outras três extremidades. Não é coincidência, portanto, que o grande tema que unifica todo esse quadrante é a democracia. Na parte esquerda superior, estão os autores da teoria democrática minimalista e da teoria da escolha racional como Kenneth Arrow, Anthony Downs, Joseph Schumpeter, Robert Dahl, Guillermo O’Donnell, Adam Przeworski etc. Coerentemente, essa é uma área de transição para o quadrante anterior onde estão localizados os autores neoinstitucionalistas. Na camada mais externa da parte direita superior estão autores ligados à teoria política normativa como Amartya Sen, John Rawls, Leonardo Avritzer, Norberto Bobbio, já em transição 
para o quadrante 1.1, onde estão as teóricos clássicos. A região interna da parte direita superior é habitada por autores preocupados com a relação entre Estado e sociedade como Claus Offe, Theda Skocpol, Mancur Olson, Gosta Esping-Andersen, T. H. Marshall etc., misturados a autores que estudam o comportamento político, inclusive sob a ótica da cultura política, como Robert Putnam, Seymour Lipset, José A. Moisés, Gabriel Almond e Sidney Verba. Na metade inferior do quadrante temos uma coleção mais eclética de autores que estudam a democracia no Brasil sob vários aspectos, entre eles eleições, judiciário, desenvolvimento, entremeados a autores da transitologia. Encontramos nessa região Lourdes Sola, Marcus Figueiredo, Bolívar Lamounier, Wanderley Guilherme dos Santos, Phillipe Schmitter, Gláucio Soares, Maria Tereza Sadek, Guillermo O’Donnell, Eli Diniz, Renato Boschi etc.

Em resumo, é possível indicar que as referências predominantes na revista DADOS nos últimos 50 anos foram extraídas de nichos temáticos como Instituições Políticas, Democracia e Eleições, Teoria Política, Estado e Sociedade, Teoria Sociológica, Pensamento Social e Político Brasileiro e Antropologia ${ }^{11}$. A Figura 2 reapresenta a Análise de Correspondências contida na Figura 1, porém acrescida da posição desses eixos temáticos predominantes.

\section{ANÁLISE DE TÓPICOS}

As análises que buscam entender como os textos de uma determinada área acadêmica se distribuem por temáticas específicas costumam empregar tipologias baseadas na autoridade do conhecimento do autor sobre o campo. Parte-se de uma lista de temas construída de modo intuitivo e muitas vezes apriorístico para, em seguida, encaixar os textos nela. Embora esse tipo de estratégia metodológica possa apresentar resultados relevantes, é sempre difícil avaliar em que medida o temário utilizado na classificação está de fato adequado ao corpus analisado. Apenas para citar um exemplo, uma tipologia temática para os textos publicados por DADOS poderia considerar "estudos da democracia" como uma de suas categorias, o que certamente permitiria perceber o quanto tal assunto predominou no periódico. Porém, uma análise mais minuciosa poderia preferir fragmentar tal temática em categorias mais específicas como "estudos eleitorais", "estudos de partidos políticos", "estudos do Estado de direito" etc. Nessa segunda hipótese, a 
50 Anos da Revista DADOS: Uma Análise Bibliométrica do seu Perfil...

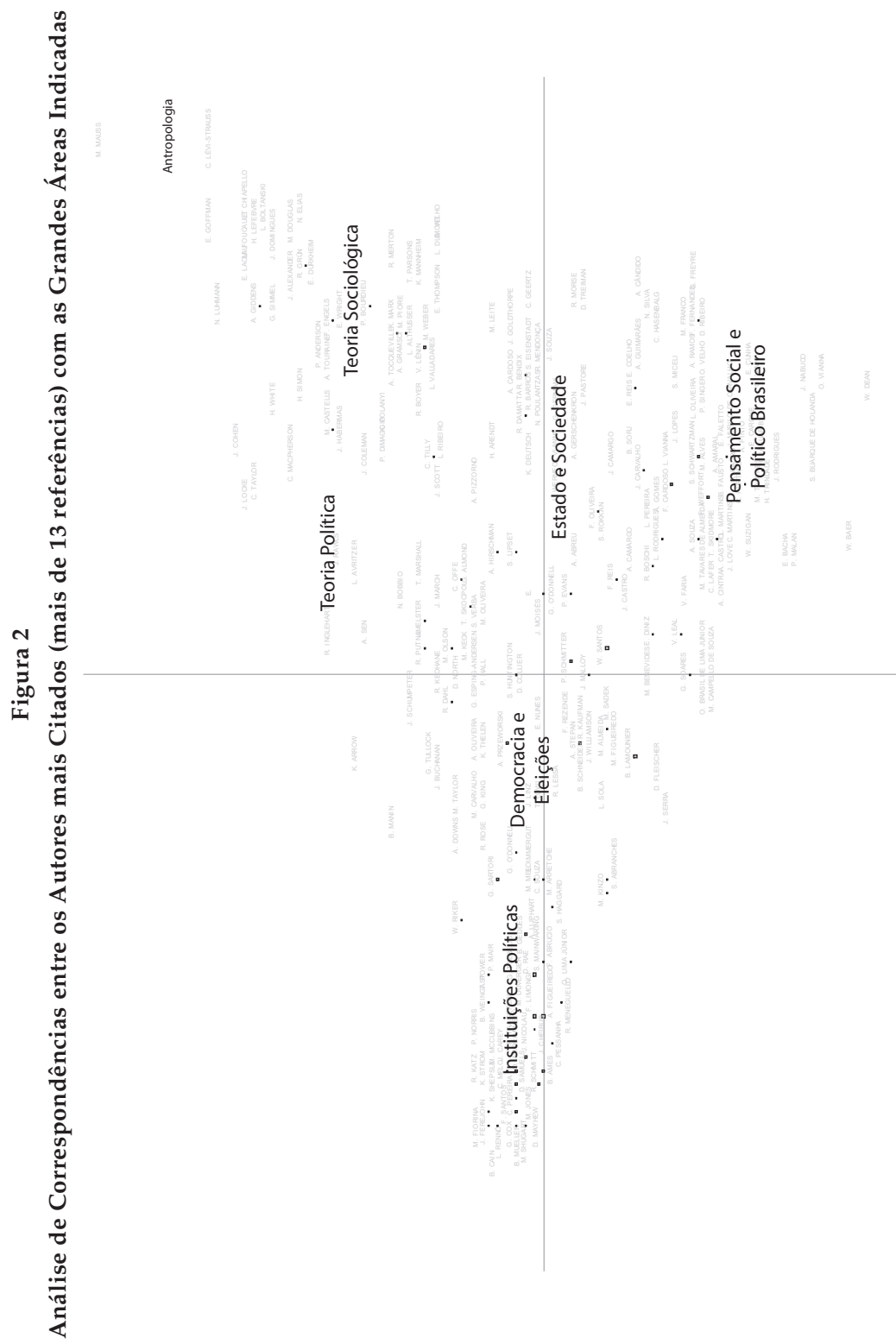


preponderância do tema da democracia se diluiria em outras classificações, levando a resultados e conclusões distintas.

É difícil escapar da arbitrariedade na identificação de grandes áreas e abordagens. A classificação proposta por nós logo acima sofre do mesmo problema. Por mais que os nichos de fontes bibliográficas pareçam ser indicação clara de uma identidade epistêmica, há sempre a possibilidade de classificações alternativas ou de áreas nas quais a distribuição de fontes não parece convergir para um determinado rótulo.

Há, contudo, alguns métodos indutivos que permitem a construção de tipologias em um diálogo mais estreito com as próprias características do corpus. Como já mencionado na nota metodológica, empregamos aqui a técnica da Modelagem de Tópicos - Topic Modeling - para auxiliar na identificação das temáticas mais recorrentes na revista DADOS. Essa técnica foi aplicada às palavras contidas nos resumos em inglês dos artigos da revista, gerando como resultado listas de resumos lexicamente semelhantes e que, portanto, podem ser categorizados como pertencentes a uma mesma temática ${ }^{12}$. Além dessas listas, a modelagem de tópicos calcula as probabilidades que um determinado texto do corpus se encaixe em um dos tópicos definidos por indução do léxico do abstract. Essa lista, por seu turno, pode ser modificada de acordo com o julgamento do analista. Logo, a modelagem de tópicos é útil por fornecer uma primeira classificação temática que serviu de base para uma reclassificação interpretativa.

Ao empregar esse segundo método, pretendemos testar a robustez de nosso esquema de classificação. Ele foi primeiro gerado pela análise de cocitações, método que em si não envolve nenhuma análise semântica, a não ser a identificação final dos clusters. Agora empregamos um método que é de natureza léxica, ou seja, muito mais próximo da semântica. É claro que ainda vai sobrar para nós, humanos, a tarefa de atribuirmos significado aos resultados.

Abaixo, apresentamos a lista dos doze tópicos identificados a partir do vocabulário dos abstracts e remodelados por nós em uma segunda análise. Como era de se esperar, artigos que debatem temas relacionados à democracia ou ao processo democratização preponderaram na revista, uma decorrência de sua linha editorial inicial. Em segundo lugar, aparecem os trabalhos sobre mercado, trabalho, desenvolvimento e indústria, seguido dos artigos focados na teoria sociológica e no pensamento social. Em quarto lugar, se encontram os textos sobre desigualdades e 
estratificação social em suas múltiplas dimensões, seguidos dos artigos sobre ação coletiva, movimentos sociais e sindicalismo em quinto; políticas públicas e avaliação governamental em sexto; e teoria e pensamento político em sétimo.

Deve-se destacar, porém, que a modelagem de tópicos apresentou um problema específico quando aplicada aos abstracts dos artigos de DADOS. Textos teóricos sobre o conceito de democracia e seus correlatos poderiam ser encaixados tanto na categoria "democracia, transitologia e eleições" quanto na rubrica "teoria política e pensamento políti$\mathrm{co}^{\prime \prime}$. Os resultados da modelagem de tópicos indicaram, contudo, que o léxico desses textos se aproximava mais da primeira categoria e, portanto, decidimos encaixá-los nela.

Artigos sobre tópicos relacionados à democracia predominam na DADOS desde a sua fundação, embora se tornem mais numerosos en-

\section{Gráfico 8}

Lista de Tópicos Identificados de acordo com o Percentual de Textos

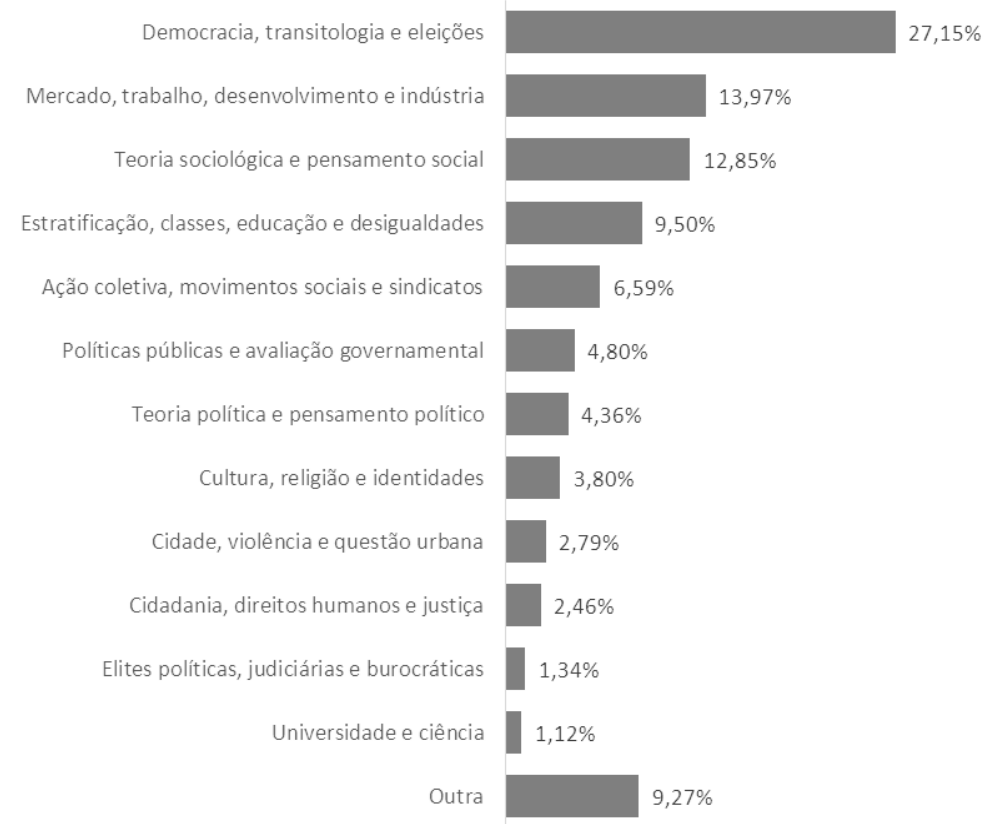

Fonte: Os autores, a partir de informações da revista DADOS. 
tre 2001 e 2005 (Gráfico 9). Embora perca espaço na revista depois desse período, ainda hoje é o tópico sobre o qual versa a maior parte dos artigos. Os textos sobre transitologia dominavam essa rubrica nos primeiros quinquênios, enquanto debates sobre aprofundamento da democracia predominam nos últimos. Vale destacar que o debate sobre a transição e a abertura e regimes autoritários chega na DADOS antes mesmo de o tema atrair uma atenção maior na década de 1980. Os artigos sobre mercado, trabalho, desenvolvimento e indústria atingiram seu pico entre 1966-1975, mas desde então perdem importância relativa. Isso se deve a múltiplas razões. $\mathrm{O}$ debate sobre o desenvolvimento econômico e político era dominante na academia brasileira e estrangeira desde meados da década de 1950 até a década de 1970. Teoria da modernização, os trabalhos da CEPAL e de seus precursores e as teorias do desenvolvimento político são exemplos importantes de contribuições a esse grande tema. $\mathrm{O}$ tema do desenvolvimento era muito presente no Instituto Superior de Estudos Brasileiros (ISEB), instituição precursora do antigo IUPERJ, instituto ao qual pertence a DADOS

\section{Gráfico 9}

Quantidade Relativa de Textos dos Sete Tópicos mais Recorrentes em DADOS, por Quinquênio

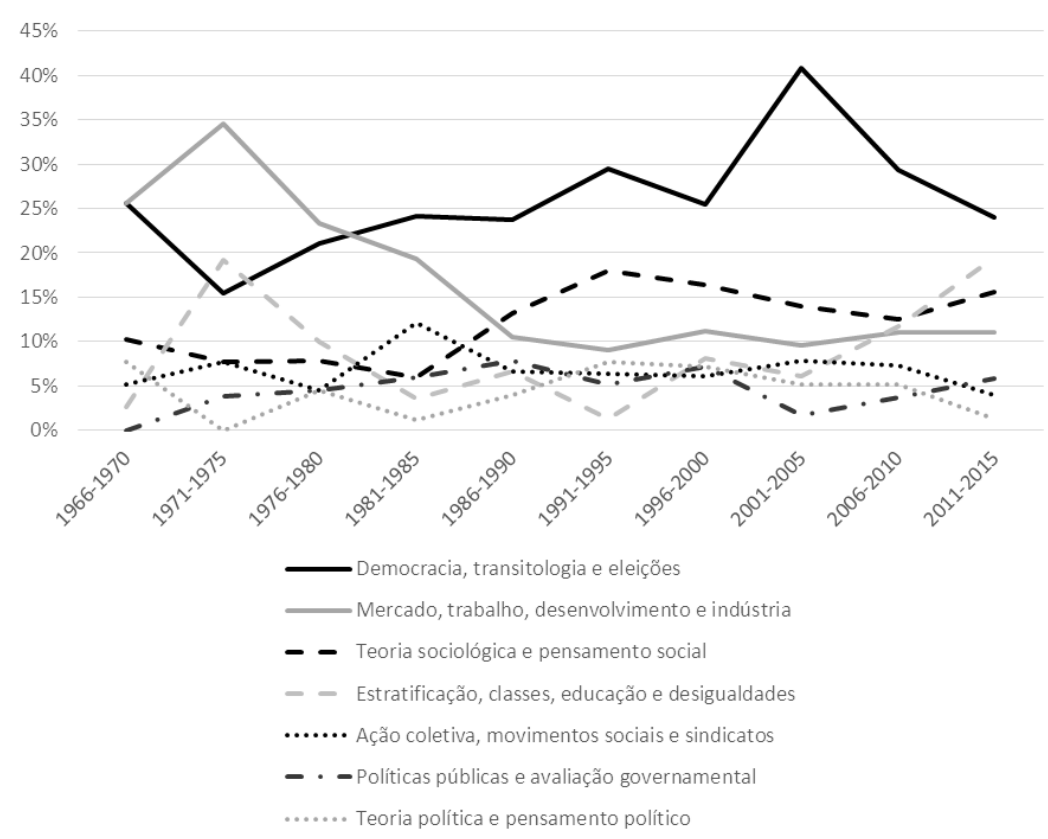

Fonte: Os autores, a partir de informações da revista Dados. 
(agora IESP-UERJ). É compreensível que nos primeiros anos da revista o tema esteja ainda bem presente na pauta. Por fim, esse período assistiu ao recrudescimento do regime militar, o que deve ter tido um efeito sobre a produção acadêmica, seja pela ameaça da repressão ao pensamento mais propriamente político, seja pela alienação e pessimismo causado pela supressão da democracia.

De meados da década de 1980 até a década passada, os textos sobre teoria sociológica e pensamento social assumiram a segunda posição na lista de tópicos mais recorrentes, mas perderam esse posto nos últimos dez anos para os textos sobre estratificação, classes, educação e desigualdades. A despeito dessas variações, é possível perceber que o temário dos artigos da DADOS se alterou pouco, sobretudo da década de 1990 até os dias de hoje.

\section{CONCLUSÕES}

No artigo que escreveram sobre a produção de teses de doutorado, Werneck Vianna et al. (1998) apresentam um paralelo curioso para explicar o perfil das Ciências Sociais em nosso país. Dizem os autores que na Alemanha o idealismo fez no âmbito do espírito a revolução que em outros países se deu "efetivamente". No Brasil, proclamam, país "igualmente de capitalismo retardatário", as Ciências Sociais têm papel similar, tentando explicar o fato de termos "ingressado no moderno sem uma revolução". Sem entrar no mérito de tal comparação e na propriedade do uso de conceitos como "moderno", vale prestar atenção para a conclusão à qual os autores chegam rapidamente: de que no Brasil "a intelligentzia das ciências sociais intervém ex-post, quando a passagem para o moderno já se cumpriu de modo conservador, restando a ela um papel 'explicativo'" (Werneck Vianna et al., 1998:351). Nosso estudo da revista DADOS revela bem o contrário.

Em seus 50 anos de existência a DADOS contribuiu para a profissionalização das Ciências Sociais brasileiras ao se constituir como um periódico pioneiro na implantação de normas da comunicação científica. Isso não significou, porém, que a revista se fechou em querelas acadêmicas herméticas, distanciando-se dos temas candentes do debate público brasileiro. Ao contrário, os artigos que nela foram publicados buscaram, em sua grande maioria, construir uma ponte entre as grandes temáticas que marcaram o debate público nacional e as abordagens metodológicas e teóricas criadas no âmbito das Ciências Sociais. 
Da análise de cocitações, foi possível perceber a importância de referências bibliográficas de sete grandes áreas: Instituições Políticas; Democracia e Eleições; Teoria Política; Estado e Sociedade; Teoria Sociológica; Pensamento Social e Político Brasileiro; e Antropologia. Ou seja, nas páginas de DADOS o tema da democracia teve um papel preponderante, ao longo de um período em que o país saía de um regime autoritário e lentamente construía novas instituições democráticas. $\mathrm{O}$ debate sobre instituições democráticas, tão crucial para nosso processo de democratização, teve na revista a sua mais importante referência, basta ver a coleção de artigos fundamentais sobre o tema acumulada ao longo dos anos.

Já a análise de tópicos indicou doze temas preponderantes, a saber: Democracia, transitologia e eleições; Mercado, trabalho, desenvolvimento e indústria; Teoria sociológica e pensamento social; Estratificação, classes, educação e desigualdades; Ação coletiva, movimentos sociais e sindicatos; Políticas públicas e avaliação governamental; Teoria política e pensamento político; Cultura, religião e identidades; Cidade, violência e questão urbana; e Cidadania, direitos humanos e justiça. A análise de tópicos revela, além da preocupação central com as instituições democráticas, a presença de outros tópicos fundamentais para o processo democrático, como as políticas públicas, os movimentos sociais e as desigualdades sociais - tema fundamental em país que ainda padece desse mal. Novamente, a produção acadêmica aqui se revela como contemporânea aos fatos, à dinâmica social e política, e não ex-post. A sincronia é notável: as referências predominantes nas primeiras décadas da revista evidenciam a importância das controvérsias em torno do desenvolvimento econômico do país e dos estudos de transição. Nas últimas décadas, o debate sobre o desenvolvimento econômico cedeu parte do seu espaço para os estudos de nossas desigualdades sociais e para as reflexões teóricas sobre a sociedade moderna e brasileira. Os textos sobre democracia também se reinventaram, deslocando-se das discussões sobre a transição democrática para análises mais específicas da nossa dinâmica eleitoral e reflexões mais filosóficas sobre como aprofundar a democracia no país.

Apesar de ter publicado textos das mais diversas áreas das Ciências Humanas e uma vocação multidisciplinar, há uma predominância de textos assinados por cientistas políticos e sociólogos na revista. Isso traduz em grande medida a vocação inicial da revista e do instituto que a abrigou, o antigo IUPERJ, atual IESP-UERJ. 
A revista, porém, ainda tem desafios a enfrentar. Ainda que a razão entre o número de autores e autoras que publicam em DADOS venha se tornando cada vez mais equânime, os homens ainda predominam e mulheres ainda publicam mais em coautoria do que homens, em termos relativos. Isso reflete, de certo modo, a estrutura sexista que ainda subsiste nas Ciências Sociais brasileiras, a despeito dos avanços conquistados nas últimas décadas.

Resta saber, também, qual será o efeito dos eventos recentes da política e da sociedade brasileira sobre uma revista tão dedicada ao debate sobre a democracia, entendida aqui em sentido amplo. Muitas das categorias mobilizadas no debate público atual para dar sentido a esse processo foram difundidas a partir da DADOS, como, por exemplo, o conceito de presidencialismo de coalizão (Abranches, 1988). É de se esperar, portanto, que os eventos tenham impacto na reflexão acadêmica e, portanto, na temática dos textos publicados na revista. De todo modo, esperamos que DADOS continue sendo um termômetro para avaliar não apenas a produção acadêmica das Ciências Sociais brasileiras, mas, sobretudo, o compromisso político que elas devem ter.

(Recebido para publicação 5 de outubro de 2016)

(Aprovado 5 de dezembro de 2016) 


\section{NOTAS}

1. Nos Estados Unidos e em alguns países europeus os livros também passam por processo de revisão por pares. Aqui no Brasil, entretanto, esse procedimento é ainda raro.

2. O documento de área da Ciência Política, publicado como resultado da última avaliação trienal da CAPES (2010-2012) contém o seguinte trecho referente à qualificação de periódicos: "Procurou-se adotar pontos de corte mais claros para a inclusão de periódicos nos estratos A1, A2 e B1. Para ser classificado como A, um periódico deverá integrar a Base SCImago. Para ser B1, deverá estar no SCImago ou no SciELO. Para diferenciar os estratos A1 e A2, considerou-se, entre outros, o fator de impacto (JCR e/ou SJR) das revistas internacionais e para as revistas brasileiras, o percentual de artigos com participação de autores estrangeiros". Fonte: <https:/ / www.capes.gov. $\mathrm{br} /$ images / stories / download / avaliacaotrienal/Docs_de_area /CI\%C3\%A Ancia_Pol\%C3\%ADtica_doc_area_e_comiss\%C3\%A3o_21out.pdf $>$.

3. Villas Bôas trabalhou com uma noção ampliada de Ciências Sociais que incluiu não apenas Sociologia, Antropologia e Ciência Política, mas também História, Demografia, Economia Política e Geografia Humana (Villas Bôas, 2007:37).

4. Tais indexadores são organizados de acordo com o padrão XML (eXtensible Markup Language).

5. Para mais detalhes sobre a construção e a análise de ACSs, cf. Benzécri (1992) e Greenacre (1993).

6. O script utilizado foi desenvolvido para identificar os tópicos recorrentes em textos em inglês. Por isso, preferimos utilizar os abstracts em detrimento dos resumos em português. Além disso, durante uma grande parte de sua existência, a revista DADOS não publicou resumos em português, o que serviu como razão adicional para a escolha dos abstracts.

7. Este número é diferente daquele mencionado nos demais textos desta coletânea porque decidimos não incluir os artigos publicados no início deste ano e por conta das demais exclusões mencionadas na seção anterior.

8. Para diferenciar nos gráficos os nomes dos autores de artigos e dos citados, usamos padrões de citação distintos. As referências aos autores de artigos aparecem sempre na ordem usual "Nome + Sobrenome maiúsculo", enquanto as referências aos citados obedecem o modelo "Inicial maiúscula + Sobrenome maiúsculo".

9. A inclusão de todos os autores ou de autores pouco citados tornaria a representação gráfica em uma galáxia com tantos pontos que dificultaria a leitura e interpretação.

10. Para uma discussão acerca das especificidades das categorias pensamento social brasileiro e pensamento político brasileiro ver Lynch (2016).

11. Gostaríamos de agradecer aos professores Cesar Guimarães, Fabiano Santos e Carlos Costa Ribeiro pela ajuda com a identificação dos clusters.

12. Antes de aplicar a técnica, os textos dos abstracts foram limpados de modo a suprimir pronomes, artigos, preposições e outras palavras sem valor semântico, e a isolar os radicais das palavras de suas derivações e flexões. Em seguida, foram suprimidas as palavras pouco e muito recorrentes, deixando apenas aquelas que permitiriam a comparação dos textos do corpus. Após sucessivas divisões temáticas do corpus, decidimos operar com uma lista de vinte assuntos predominantes. 


\section{REFERÊNCIAS BIBLIOGRÁFICAS}

ABRANCHES, Sérgio. (1988), "Presidencialismo de Coalizão: O Dilema Institucional Brasileiro". DADOS - Revista de Ciências Sociais, vol. 31, no 1, pp. 5-34.

ALFARO REDONDO, Ronald; VARGAS CULLELL, Jorge. (2005), “Ciencia Política en Costa Rica: Búsqueda de Identidad Disciplinaria". Revista de Ciencia Política (Santiago), vol. 25, pp. 124-135.

ALTMAN, David. (2006), “From Fukuoka to Santiago: Institutionalization of Political Science in Latin America". PS: Political Science and Politics, vol. 39, no 1, pp. 196-203.

BENOIT, Kenneth; MARSH, Michael. (2009), “A Relative Impact Ranking of Political Studies In Ireland". The Economic and Social Review, vol. 40, no 3, pp. 269-298.

BENZÉCRI, Jean-Paul. (1992), Correspondence Analysis Handbook Statistics. New York, Marcel Dekker Inc.

BOURDIEU, Pierre. (1988), Homo Academicus. Stanford, CA, Stanford University Press. . (2007), A Distinção: Crítica Social do Julgamento. São Paulo, Zouk e Edusp.

BREMBS, Björn; BUTTON, Katherine; MUNAFÒ, Marcus. (2013), “Deep Impact: Unintended Consequences of Journal Rank". Frontiers in Human Neuroscience, vol. 7, no 291.

BUTLER, Linda; MCALLISTER, Ian. (2009), "Metrics or Peer Review? Evaluating the 2001 UK Research Assessment Exercise in Political Science". Political Studies Review, vol. 7, no 1, pp. 3-17.

DIGIAMPIETRI, Luciano A. et al. (2012), "Minerando e Caracterizando Dados de Currículos Lattes". Trabalho apresentado na Brazilian Workshop on Social Network Analysis and Mining (BraSNAM), Sociedade Brasileira de Computação, Curitiba, 17 de julho.

EDITORIAL. (2015), “The Story of Fake Impact Factor Companies and How We Detected Them". Electron Physician, no 5.

. (2016), “Time to Remodel the Journal Impact Factor”. Nature, vol. 535 o 466.

FERES JÚNIOR, João; CAMPOS, Luiz Augusto; ASSUMPÇÃO, San Romanelli. (2016), "Teoria Política Normativa", in L. Avritzer; C. Milani; M. S. Braga (orgs.), A Ciência Política no Brasil: 1960-2015. Rio de Janeiro, FGV Editora, pp. 217-274.

FERRAZ, Sérgio Eduardo. (2004), "Os Dados do Normativo: Apontamentos sobre a Recepção das Teorias Contemporâneas de Justiça no Brasil (1990-2003) ". BIB, no 58, pp. 131-157.

GARFIELD, Eugene. (1998), "The Impact Factor and Using It Correctly". Der Unfallchirurg, vol. 101, no 6, pp. 413-414.

GREENACRE, Michael. (1993), Correspondence Analysis in Practice. Boca Raton, Chapman \& Hall/CRC.

GREENBERG, Steven A. (2009), "How Citation Distortions Create Unfounded Authority: Analysis of a Citation Network". British Medical Journal, vol. 339, no b2680, pp. 210-213. 
HIRSCH, Jorge E. (2005), “An Index to Quantify an Individual's Scientific Research Output". Proceedings of the National Academy of Sciences of the United States of America, vol. 102, no 46, pp. 16569-16572.

HIX, Simon. (2004), "A Global Ranking of Political Science Departments". Political Studies Review, vol. 2, no 3, pp. 293-313.

KUHN, Thomas. (1962), The Structure of Scientific Revolutions. Chicago, University of Chicago Press.

LEITE, Fernando. (2010), "Posições e Divisões na Ciência Política Brasileira Contemporânea: Explicando sua Produção Acadêmica". Revista de Sociologia e Política, vol. 18, pp. 149-182.

. (2015), O Campo de Produção da Ciência Política Brasileira Contemporânea: Uma Análise Histórico-estrutural de seus Princípios de Divisão a partir de Periódicos, Áreas e Abordagens. Tese (Doutorado em Sociologia), Universidade Federal do Paraná, Curitiba.

. (2016), "The Stratification of Diversity: Measuring the Hierarchy of Brazilian Political Science". Brazilian Political Science Review, vol. 10.

; CODATO, Adriano. (2013), “Autonomização e Institucionalização da Ciência Política Brasileira: O Papel do Sistema Qualis-Capes". Revista de Discentes de Ciência Política da UFSCAR, vol. 1, no 1, pp. 1-21.

LYNCH, Christian Edward Cyril. (2016), “Cartografia do Pensamento Político Brasileiro: Conceito, História, Abordagens". Revista Brasileira de Ciência Política, no 19, pp. 75-119.

MARENCO, André. (2015), “When Institutions Matter: CAPES and Political Science in Brazil". Revista de Ciência Política, vol. 35, no 1, pp. 33-46.

. (2016), “Cinco Décadas de Ciência Política no Brasil: Institucionalização e Pluralismo", in L. Avritzer; C. Milani e M. S. Braga (orgs.), A Ciência Política no Brasil: 1960-2015. Rio de Janeiro, FGV Editora, pp. 141-164.

MELO, Manuel Palácios Cunha. (1997), As Ciências Sociais no Brasil Contemporâneo, Sociologia. Tese (Doutorado em Sociologia), IUPERJ, Rio de Janeiro.

. (1999), Quem Explica o Brasil. Juiz de Fora, Editora UFJF.

MOUSTAFA, Khaled. (2015), "The Disaster of the Impact Factor". Science and Engineering Ethics, vol. 21, no 1, pp. 139-142.

MUGNAINI, Rogério; JANNUZZI, Paulo de Martino; QUONIAM, Luc. (2004), “Indicadores Bibliométricos da Produção Científica Brasileira: Uma Análise a partir da Base Pascal." Ciência da Informação, vol. 33, no 2, pp. 123-131.

OECD (Organisation for Economic Co-operation and Development). (2013), Bibliometrics, em OECD Frascati Manual: The Organisation for Economic Co-operation and Development. Paris, OECD Publishing.

OLIVEIRA, Lilian; NICOLAU, Jairo. (2014), A Produção da Ciência Política Brasileira: Uma Análise dos Artigos Acadêmicos (1966-2013). Trabalho apresentado no IX Encontro da ABCP. Brasília, 4-7 de agosto. 
ROCHA CARPIUC, Cecilia. (2016), "Women and Diversity in Latin American Political Science". European Political Science, vol. 15, no 4, pp. 457-475.

RUSSELL, Andrew. (2009), "Retaining the Peers: How Peer Review Triumphs over League Tables and Faulty Accounting in the Assessment of Political Science Research". Political Studies Review, vol. 7, no 1, pp. 63-72.

SANTOS, Maria Helena de Castro; COUTINHO, Marcelo J. V. (2000), "Política Comparada: Estado das Artes e Perspectivas no Brasil". BIB, no 54, pp. 3-146.

SOARES, Gláucio Ary Dillon; SOUZA, Cíntia Pinheiro Ribeiro de; MOURA, Tatiana Whately de. (2010), "Colaboração na Produção Científica na Ciência Política e na Sociologia Brasileiras”. Sociedade e Estado, vol. 25, no 3, pp. 525-538.

TAVARES, Francisco Mata Machado; OLIVEIRA, Ian Caetano de. (2016), “Omissões e Seletividades da Ciência Política Brasileira: Lacunas Temáticas e seus Problemas Sócio-Epistêmicos". Revista Brasileira de Ciência Política, no 19, pp. 11-45.

VALLE SILVA, Nelson do. (1999), Relatório de Consultoria sobre Melhoria do Treinamento em Ciência Social Quantitativa e Aplicada no Brasil. Rio de Janeiro, Laboratório Nacional de Computação Científica.

VEYNE, Paul. (1998), Como se Escreve a História. Brasília, Editora da UnB.

VILLAS BÔAS, Glaucia. (2007), A Vocação das Ciências Sociais no Brasil: Um Estudo da sua Produção em Livros no Acervo da Biblioteca Nacional (1945-1966). Rio de Janeiro, Fundação Biblioteca Nacional.

WEALE, Albert. (2009), “Metrics versus Peer Review?”. Political Studies Review, vol. 7, no 1, pp. 39-49.

WERNECK VIANNA, Luiz et al. (1998), “Doutores e Teses em Ciências Sociais”. DADOS - Revista de Ciências Sociais, vol. 41, no 3, pp. 453-516. 


\section{RESUMO}

50 Anos da Revista DADOS: Uma Análise Bibliométrica do seu Perfil Disciplinar e Temático

O artigo traça o perfil autoral, disciplinar, bibliográfico e temático da revista DADOS por meio de uma análise bibliométrica de todos os textos publicados pelo periódico nos seus 50 anos de existência (1966-2015). A composição da base se deu pelo processamento dos textos indexados na plataforma SciELO e da leitura e codificação manual dos volumes mais antigos da revista. Diferentes técnicas para o estudo de corpora linguísticos foram utilizadas para delinear o perfil das bibliografias recorrentes, mormente a Análise de Correspondências Simples, e o perfil temático dos textos, sobretudo a Modelagem de Tópicos. Os resultados sugerem que a revista privilegiou artigos sobre as temáticas públicas prementes de cada momento histórico, aliando rigor metodológico ao compromisso com as questões públicas mais candentes no país e no mundo.

Palavras-Chave: Ciências Sociais; revista DADOS; bibliometria; periódicos científicos; análise de conteúdo

\section{ABSTRACT \\ Fifty Years of Revista DADOS: A Bibliometric Study of its Disciplinary and Thematic Profiles}

In this article we employ bibliometric techniques to examine the authorial, disciplinary, bibliographical, and thematic profiles of the Journal DADOS, from its foundation to the present (1966-2015). The database was amassed using two different methods, the periodical's most recent output was scraped from the website SciELO in XML format while the older issues had to be scanned and its bibliography extracted by painstakingly copying and pasting each entry. We employed two techniques to analyze the material: Correspondence Analysis, to determine the patterns of co-citations and thus to chart the bibliographical map of the periodical, and Topic Modeling, to identify the main themes and approaches in the corpus. The results show that Dados privileged themes and debates that were most relevant in each period, in a constant attempt to bring together methodological rigor and public relevance.

Keywords: Social Sciences; revista DADOS; bibliometrics; scientific periodicals; topic modeling 


\section{RÉSUMÉ}

Les 50 Ans de la Revue DADOS: Une Analyse Bibliométrique de son Profil Disciplinaire et Thématique

L'article analyse le profil disciplinaire, bibliographique, thématique et des auteurs de la revue DADOS à partir de quelques techniques bibliométriques appliquées aux textes publiés lors des cinquante dernières années (1966-2015). Le corpus linguistique est formé, d'une part, par les textes de la revue disponibles sur le site Internet Scielo.br et, d'autre part, par des articles académiques plus anciens. On a utilisée plusieurs techniques d'analyse de corpus linguistiques pour identifier les références bibliographiques récurrentes, grâce notamment l'Analyse de Correspondances, et le profil thématique des textes, avec, entre autres, l'Analyse des Topiques. L'étude montre que le périodique scientifique a privilégié pendant son histoire les thématiques publiques les plus importantes pour le pays, en combinant rigueur méthodologique et compromis politique.

Mots-clés: Sciences sociales; revue DADOS; bibliométrie; périodiques scientifiques; analyse de contenu

\section{RESUMEN}

\section{Años de la Revista DADOS: Un Análisis Bibliométrico de su Perfil Disciplinario y Temático}

El artículo traza el perfil de autor, disciplinario, bibliográfico y temático de la revista DADOS por medio de un análisis bibliométrico de todos los textos publicados en el periódico en sus 50 años de existencia (1966-2015). La composición de la base se hizo mediante el procesamiento de los textos indexados en la plataforma Scielo y la lectura y codificación manual de los volúmenes más antiguos de la revista. Se utilizaron diferentes técnicas para el estudio de corpus lingüísticos para delinear el perfil de las bibliografías recurrentes, principalmente el análisis de correspondencias simples, y el perfil temático de los textos, especialmente el modelado de temas. Los resultados sugieren que la revista se enfocó en artículos sobre los temas públicos apremiantes de cada momento histórico, uniendo el rigor metodológico y el compromiso con las cuestiones públicas más candentes del país y del mundo.

Palabras clave: Ciencias Sociales; revista DADOS; bibliometría; periódicos científicos; análisis de contenido 